
de la dinámica del mercado laboral en Popayán Colombia. Económicas CUC, 37(1), 135-176. DOI: http://dx.doi.org/10.17981/econcuc.37.1.2016.07

\title{
Análisis de la dinámica del mercado laboral en Popayán - Colombia ${ }^{1}$
}

DOI: http://dx.doi.org/10.17981/econcuc.37.1.2016.07

\author{
Andrés Mauricio Gómez Sánchez ${ }^{2}$ \\ Juliana Isabel Sarmiento Castillo ${ }^{3}$ \\ Claudia Liceth Fajardo Hoyos ${ }^{4}$
}

\begin{abstract}
Resumen
El artículo analiza la dinámica del mercado laboral en la ciudad de Popayán desde una mirada económica e institucional, dada la falta de estudios sobre el tema que han impedido implementar políticas que disminuyan los altos índices de desempleo en el último lustro. Para lograrlo, se utilizó la información generada por el Departamento Administrativo Nacional de Estadística (DANE) a través de la Gran Encuesta Integrada de Hogares (GEIH), así como datos obtenidos por instituciones oficiales y privadas del ámbito local, las cuales cumplen un papel protagónico en materia de empleo en Popayán. Los resultados muestran que la economía de la región, se basa en el sector comercial y de servicios, lo cual limita la generación de empleos estables y de mejor cualificación. Situación que repercute de forma directa en los ingresos de los trabajadores. De otro lado, se encuentra que el desempleo ataca en mayor medida a las mujeres entre 14 y 26 años, y de manera contraria, institucionalmente se determina que hay una mayor participación de los hombres en las capacitaciones, así como en los subsidios al desempleo en varios rangos de edad. Se definen recomendaciones para hacer minimizar el impacto generado por la situación descrita.
\end{abstract}

Palabras clave: mercado Laboral; empleo; desempleo; desempleo femenino; empresas de servicios temporales.

Recibido: 23.9.2015 Devuelto para revisión: 30.10.2015 Aceptado: 4.12.2015

\footnotetext{
${ }^{1}$ Artículo científico derivado de la investigación "Diagnostico de Mercado del Municipio de Popayán”. Financiada por el Ministerio de Trabajo, Departamento de Prosperidad Social (DPS), Programa de las Naciones Unidas para el Desarrollo (PNUD) y Universidad del Cauca.

${ }^{2}$ Magíster en Economía Aplicada. Universidad del Valle-Cali, Colombia. Especialista en Gerencia de Proyectos. Universidad del Cauca. Economista, Universidad del Valle, Cali, Colombia. Docente del Departamento de Economía adscrito al Grupo de Investigación Entropía, Universidad del Cauca, Popayán, Colombia. Autor de correspondencia, amgomez@unicauca.edu.co

${ }^{3} \mathrm{PhD}$ en Ciencias Ambientales, Universidad del Cauca, Popayán, Colombia. Especialista en Finanzas, Universidad del Valle, Cali, Colombia. Economista, Universidad del Cauca, Popayán, Colombia. Docente del Departamento de Economía adscrito al Grupo de Investigación Entropía, Universidad del Cauca, Popayán, Colombia. jisarmiento@unicauca.edu.co.

${ }^{4}$ Magíster en Economía Aplicada, Universidad del Valle, Cali, Colombia. Economista, Universidad del Cauca, Popayán, Colombia Colombia. Docente del Departamento de Economía adscrito al Grupo de Investigación Entropía, Universidad del Cauca, Popayán, Colombia.cfajardo@unicauca.edu.co.

- The author; licensee Universidad de la Costa - CUC.

Económicas CUC vol. 37 no. 1, pp. 135-176. Enero - Junio, 2016 Barranquilla. ISSN 0120-3932 Impreso, ISSN 2382-3860 Online
} 


\title{
Analysis of the Dynamics of the Labor Market in Popayán - Colombia
}

\begin{abstract}
The article analyzes the dynamics of the labor market in the city of Popayán from an economic and institutional perspective, due to the lack of studies on the subject that have prevented the implementation of policies that reduce the high unemployment rates in the last five years. To achieve this, the information generated by the National Administrative Department of Statistics (DANE) was used through the Great Integrated Household Survey (GEIH), as well as data obtained by official and private institutions of the local scope, which play a leading role On employment in Popayán. The results show that the region economy is based on the commercial and services sector, which limits the generation of stable and better qualified jobs, situation that has a direct impact on the income of workers. In contrast, it is found that unemployment affects women between 14 and 26 years of age, conversely, institutionally it is determined that there is a greater participation of men in training, as well as unemployment benefits in different age. Recommendations are made to minimize the impact generated by the described situation.
\end{abstract}

Keywords: working market; job; unemployment; female unemployment; temporary service companies.

\section{Introducción}

Desde hace solo siete años atrás, la ciudad de Popayán fue incluida en la Gran Encuesta Integrada de Hogares (GEIH) realizada por el Departamento Nacional de Estadística (DANE) para las 24 ciudades más importantes del país. De acuerdo con esta entidad, la GEIH es una encuesta mediante la cual se solicita información sobre las condiciones de empleo de las personas, además de otras características generales de la po- blación, como sexo, edad, estado civil, nivel educativo y fuentes de ingresos.

A pesar de esto, la información a nivel de microdatos solo estuvo disponible al público en general de forma anonimizada a partir del año 2012. Por tal motivo, no se conocía, por ejemplo, si el desempleo era mayor en las mujeres que en los hombres, tampoco cuáles eran los rangos donde se manifestaba en mayor grado, o en qué ramas de actividad económica se ubicaban laboralmente 
los ocupados. Sumado a este alto nivel de incertidumbre en la forma cómo se manifiesta el desempleo, no se disponía de información agregada a nivel departamental y local, lo que generaba una visión reducida de la problemática del desempleo.

Del lado de la oferta, la situación era similar. La información recopilada por parte de la oficina del Ministerio de Trabajo a nivel local se desconocía, al igual que la emanada por las Cajas de Compensación Familiar. Así las cosas, no se tenían cifras de las personas beneficiadas por los programas de empleo, si existían los subsidios al desempleo, quiénes los recibían, cuál fue la dinámica de las empresas de servicios temporales, en qué campo laboral se ofrecían los trabajadores, ni mucho menos del comportamiento del fenómeno de la informalidad. Estos son algunos de las interrogantes que el presente estudio pretende resolver.

Teniendo en cuenta que Popayán y, en general el departamento del Cauca, es una de las regiones más pobres del país (incidencia del 62\%) y con mayores niveles de concentración del ingreso (Gini de 0,54), es importante conocer cuál es la dinámica del mercado laboral del departamento y de su capital, no solo desde la demanda sino también desde la oferta. El objetivo de este documento fue llenar un vacío analítico que a la postre permitió a las entidades encargadas de la política pública (policy makers), tanto a nivel local y regional, implementar planes, programas o proyectos con miras a menguar los altos niveles de desempleo que se estaban presentando en la ciudad, los cuales alcanzaron niveles alarmantes del $19 \%$ en promedio para el período de análisis, 2007-2012.

En este orden de consideraciones, esta investigación consta de siete secciones, donde la primera es la presente introducción. La segunda contiene la estructura empresarial e industrial de la ciudad de Popayán. Seguidamente, se muestra un panorama del comportamiento reciente del nivel de actividad económica del departamento y su capital. Para la cuarta sección se obtienen y se analizan los indicadores clásicos del mercado laboral a partir de la GEIH. En la cuarta, se analizan los programas de empleo implementados en la región. La sección quinta muestra la oferta de programas para acceder al empleo y trabajo, como créditos, emprendimientos, generación de ingresos y formación. A continuación se captura la asimetría que existe entre la oferta y la demanda de empleo a nivel local. Finalmente, la última sección esboza un conjunto de conclusiones al igual que recomendaciones para aminorar el desempleo regional a través de una ruta crítica de empleabilidad y estrategias de empleo. 


\section{Estructura empresarial e industrial de la ciudad de Popayán}

La estructura empresarial e industrial son elementos de análisis necesarios dentro de la dinámica laboral de una ciudad o región, ya que nos permiten poner en evidencia de alguna manera las necesidades de mano de obra y los perfiles ocupacionales que la economía requiere. La ciudad de Popayán se ha caracterizado por tener una dinámica económica diferente a la del resto del departamento, pues mientras la economía departamental gira en torno al sector agrícola, la vocación productiva de la ciudad está en el sector de servicios.

En el municipio de Popayán se encuentran registrados, a noviembre de 2012, 7.825 unidades productivas, con unos activos totales que ascienden a $\$ 1.702 .415$ millones de pesos. El sector de suministro de energía, gas y agua concentra el $47,53 \%$ ( $\$ 809.037$ millones de pesos) del total de los activos registrados por las empresas payanesas; esta alta concentración responde a la inversión de 13 sociedades y obedece a las características propias de las actividades del sector que exigen una alta inversión en la infraestructura de las empresas para ofrecer el servicio.
Por su parte, el sector de comercio concentra el 17,01\% (\$289.554 millones de $\operatorname{pesos}^{1}$ ) de la inversión en activos del municipio y es el de mayor participación en lo concerniente al número de registros, con un total de 4.176 que representan el 53,37\% del total de las empresas del municipio. Le siguen en importancia, según el número de empresas registradas, el sector hoteles y restaurantes con 840 registros, actividad inmobiliaria con 736 e industria con 598. Llama la atención que estos últimos sectores no concentran más del $13 \%$ del valor total de los activos y el $27,7 \%$ del total de empresas. Generalmente se ha considerado al sector industrial como la opción más viable para generar empleos de calidad, sin embargo, no todas las economías se soportan en ese sector, es importante una revisión de la vocación productiva y de las condiciones del departamento para saber a qué sector se debe apuntar con miras a generar nuevos puestos de trabajo.

\footnotetext{
1 Sin embargo, se debe tomar con precaución esta información, ya que las empresas pueden estar incentivadas a no declarar el valor real de sus activos, dado que esto incide en el pago de sus impuestos.
} 
Cuadro 1

Clasificación CIIU Rev. 3 A.C. de las empresas del Municipio de Popayán y activos en millones de pesos

\begin{tabular}{|c|c|c|c|c|}
\hline CIIU & $\begin{array}{c}\text { No. } \\
\text { Empresas. }\end{array}$ & $\begin{array}{c}\text { Participación } \\
\%\end{array}$ & $\begin{array}{c}\text { Total } \\
\text { Activos }\end{array}$ & $\begin{array}{c}\text { Participación } \\
\%\end{array}$ \\
\hline Agricultura, Ganadería, Caza y Silvicultura & 85 & $1,1 \%$ & $\$ 20.411$ & $1,2 \%$ \\
\hline Pesca & 3 & $0,0 \%$ & $\$ 4.628$ & $0,3 \%$ \\
\hline Explotación de Minas y canteras & 11 & $0,1 \%$ & $\$ 4.194$ & $0,3 \%$ \\
\hline Industria & 598 & $7,6 \%$ & $\$ 89.037$ & $5,2 \%$ \\
\hline Electricidad, Gas y agua & 13 & $0,2 \%$ & $\$ 809.091$ & $47,5 \%$ \\
\hline Construcción & 193 & $2,5 \%$ & $\$ 84.252$ & $5,0 \%$ \\
\hline Comercio & 4.176 & $53,4 \%$ & $\$ 289.554$ & $17,0 \%$ \\
\hline Hoteles y Restaurantes & 840 & $10,7 \%$ & $\$ 9.571$ & $0,6 \%$ \\
\hline Transporte, Almacenamiento y Comunicaciones & 440 & $5,6 \%$ & $\$ 108.965$ & $6,4 \%$ \\
\hline Intermediación Financiera & 112 & $1,4 \%$ & $\$ 3.337$ & $0,2 \%$ \\
\hline Actividad Inmobiliaria & 736 & $9,4 \%$ & $\$ 120.339$ & $7,1 \%$ \\
\hline Admón pública y Seguridad Social Obligatoria & 9 & $0,1 \%$ & $\$ 785$ & $0,1 \%$ \\
\hline Educación & 39 & $0,5 \%$ & $\$ 1.862$ & $0,1 \%$ \\
\hline Servicios sociales de salud & 164 & $2,1 \%$ & $\$ 122.520$ & $7,2 \%$ \\
\hline Otras actividades de servicios & 406 & $5,2 \%$ & $\$ 33.869$ & $2,0 \%$ \\
\hline Total & 7.825 & $100 \%$ & $\begin{array}{c}\$ \\
1.702 .415\end{array}$ & $100 \%$ \\
\hline
\end{tabular}

Fuente: elaboración propia a partir de datos de la Cámara de Comercio del Cauca (2009).

El sector agricultura, ganadería, caza y silvicultura cuenta con 85 empresas registradas y una participación tan sólo del 1,2\% del total de los activos, lo que puede entenderse como un sector con bajos niveles de utilización del capital, lo cual influye de manera directa en la productividad del sector y, por ende, en la remuneración al factor trabajo.
Según el tamaño de las empresas registradas en la Cámara de Comercio, se tiene que 7.442 de ellas son microempresas, es decir, unidades económicas que no generan más de 10 empleos y cuyos activos (sin incluir la vivienda) no superan los 500 SMMLV (Congreso de la República, Ley 590, 2010). En cuanto a las grandes em- 
Cuadro 2

Clasificación según el tamaño de las empresas del municipio de Popayán.

\begin{tabular}{lcccc}
\hline \multicolumn{1}{c}{ Tamaño } & No. Empresas & Participación \% & Total Activos & Participación \% \\
\hline Microempresa & 7442 & $95,1 \%$ & $\$ 65579$ & $3,9 \%$ \\
Pequeña & 334 & $4,3 \%$ & $\$ 290358$ & $17,1 \%$ \\
Mediana & 39 & $0,5 \%$ & $\$ 231288$ & $13,6 \%$ \\
Grande & 10 & $0,1 \%$ & $\$ 115190$ & $65,5 \%$ \\
Total & 7825 & $100 \%$ & $\$ 1.702 .415$ & $100 \%$ \\
\hline
\end{tabular}

Fuente: elaboración propia a partir de datos de la Cámara de Comercio del Cauca (2009).

presas, es decir, aquellas que generan más de 200 empleos, son 10 las registradas en la ciudad de Popayán; estas últimas concentran el $65,51 \%$ del total de los activos reportados.

La figura jurídica preponderante en la ciudad de Popayán es la persona natural, con una participación del 89,19\% (6.979 registros) del total de las empresas; las formas jurídicas Sociedades Anónimas Simplificadas y Sociedad Limitada le siguen en participación con un total de 479 y 207 registros que corresponden al $6,1 \%$ y el 2,7\%, respectivamente. Las sociedades anónimas con 67 registros, concentran un $57,68 \%$ de la participación total de los activos, le siguen las sociedades por acciones simplificadas con un $21,45 \%$ y las personas naturales con un $13,7 \%$ en la participación de los activos.
Según datos de la Cámara de Comercio, en la ciudad de Popayán se encuentran registrados 3.990 establecimientos comerciales de 10 empleados o menos (microempresa) y sólo uno de más de 200 empleados. Los pequeños establecimientos le siguen a los micro con un total de 172 registros.

Los pequeños establecimientos comerciales concentran el $51 \%$ de los activos, dejando atrás a los micro que tan sólo participan en un $12 \%$ de los mismos a pesar de tener 3.990 registros en Cámara de Comercio. Los grandes establecimientos comerciales de la ciudad, que en este caso tiene un sólo registro, tienen una participación del 13\% del valor de los activos. El crecimiento de la ciudad ha permitido la puesta en marcha de proyectos para la construcción de dos grandes establecimientos y la ampliación del existente. 
Cuadro 3

Clasificación de las empresas del municipio de Popayán según su organización jurídica.

\begin{tabular}{lcccc}
\hline \multicolumn{1}{c}{ Organización Jurídica } & $\begin{array}{c}\text { No. } \\
\text { Empresas. }\end{array}$ & $\begin{array}{c}\text { Participación } \\
\mathbf{\%}\end{array}$ & Total Activos & $\begin{array}{c}\text { Participación } \\
\mathbf{\%}\end{array}$ \\
\hline Persona Natural & 6.979 & $89,2 \%$ & $\$ 233.214$ & $13,7 \%$ \\
Sociedad Limitada & 207 & $2,7 \%$ & $\$ 113.006$ & $6,6 \%$ \\
Sociedad Anónima & 67 & $0,9 \%$ & $\$ 982.001$ & $57,7 \%$ \\
Sociedad Comandita Simple & 22 & $0,3 \%$ & $\$ 4.183$ & $0,3 \%$ \\
Sociedad Comandita Acciones & 1 & $0,0 \%$ & $\$ 558$ & $0,0 \%$ \\
Sociedades Extranjeras & 1 & $0,0 \%$ & $\$ 1$ & $0,0 \%$ \\
Empresa Asociativa de Trabajo & 17 & $0,2 \%$ & $\$ 200$ & $0,0 \%$ \\
Unipersonal & 52 & $0,7 \%$ & $\$ 4.107$ & $0,2 \%$ \\
Sociedad Anónima Simplificada & 479 & $6,1 \%$ & $\$ 365.145$ & $21,5 \%$ \\
Total & 7.825 & $100 \%$ & $\$ 1.702 .415$ & $100 \%$ \\
\hline
\end{tabular}

Fuente: elaboración propia a partir de datos de la Cámara de Comercio del Cauca (2009).

Cuadro 4

Establecimientos comerciales según tamaño y activos en millones de pesos. Popayán ${ }^{2}$

\begin{tabular}{lllll}
\hline \multicolumn{1}{c}{ Tamaño } & \multicolumn{1}{c}{ No. Empresas } & \multicolumn{1}{c}{ Participación \% } & Total Activos & Participación \% \\
\hline Microempresa & 3.990 & $95,6 \%$ & $\$ 34.801$ & $12,0 \%$ \\
Pequeña & 172 & $4,1 \%$ & $\$ 148.070$ & $51,1 \%$ \\
Mediana & 13 & $0,3 \%$ & $\$ 68.090$ & $23,5 \%$ \\
Grande & 1 & $0,0 \%$ & $\$ 38.593$ & $13,3 \%$ \\
Total & 4.176 & $100 \%$ & $\$ 289.554$ & $100 \%$ \\
\hline
\end{tabular}

Fuente: elaboración propia a partir de datos de la Cámara de Comercio del Cauca (2009).

\footnotetext{
${ }^{2} \mathrm{El}$ número de establecimientos comerciales difiere notablemente del número de las empresas registradas debido a que buena parte de las empresas con registro en Cámara de Comercio son personas naturales sin establecimiento comercial.
} 
Se espera que dichos proyectos logren a futuro la generación de nuevos empleos, lo que demandará de la política pública una orientación de la mano de obra existente hacia el perfil ocupacional requerido en dicho sector.

\section{Estructura y dinámica económica del Cauca y Popayán}

Ciclos y crecimiento económico. De acuerdo con las cifras registradas por el DANE para el departamento del Cauca, el nivel de su actividad económica se ha caracterizado en los últimos años por presentar comportamientos cíclicos muy cortos. Es decir, las expansiones y recesiones del PIB real tan sólo han guardado un espacio de dos años entre ellas. ${ }^{3}$

En el periodo 2006-2008 ocurre el primer ciclo, para 2008-2010 existe otro, y ya para el 2011 se inicia uno nuevo. En términos más precisos, en el primer ciclo, el crecimiento de la economía había alcanzado los 3,14 puntos porcentuales, el cual distaba de su crecimiento en años anteriores, básicamente por dos fenómenos: la disminución presentada en la inversión neta en el 2007,

\footnotetext{
${ }^{3}$ No se puede determinar el PIB para la capital, Popayán, debido a que no se cuenta con la información oficial del DANE.
}

explicada por la disolución de empresas en el sector industrial, la cual dejó de aportar al PIB 1,3 billones de pesos; y de otro lado, la caída en las exportaciones (12,1\%) que tuvieron lugar en el sector azucarero. Pero para 2008, a pesar de que la crisis financiera azotaba a los países globalizados, incluyendo el nuestro, a nivel departamental la situación era un poco diferente. El auge de las captadoras ilegales de dinero, denominadas "pirámides", en este periodo protegió la economía regional de la crisis, alcanzando crecimientos del PIB por encima del nacional $(4,54 \%$ frente a $3,55 \%)$, de acuerdo a Miller y Gómez (2011).

En el segundo ciclo, la recesión de 2009 se explicó básicamente por el desplome de las pirámides causando un impacto considerable en los niveles de actividad económica regional, ya que se retornó al $3 \%$ de crecimiento de años anteriores. Aproximadamente, el $80 \%$ de los inversionistas que perdieron dinero eran de Popayán, siendo el sector comercial y hotelero los mayores perjudicados, ya que sus pérdidas alcanzaron los 12,6 billones de pesos (Miller y Gómez, 2011). Para 2010, la economía caucana experimentó una expansión bastante fuerte, mostrando un crecimiento del $6,72 \%$, mientras que el nacional era del $4 \%$. Esta dinámica obedeció a dos aspectos: en primer lugar, el sector de la construcción, en donde las obras nuevas con destino a vi- 
vienda repuntó con un incremento del $37 \%$, y en segundo lugar, la inversión neta en el departamento ascendió a $\$ 68.627$ millones de pesos, es decir, experimentó un alza del $85,3 \%$.

En términos comparativos, el ciclo económico del Cauca (CPIBC) y el de Colombia (CPIBNAL), para los últimos años, muestra una periodicidad más amplia entre expan- siones y recesiones a nivel nacional ${ }^{4}$. La duración del ciclo colombiano, como lo muestra el gráfico 1, es de aproximadamente tres años, mientras que a nivel departamental, como se dijo anteriormente, se acerca a dos años. La volatilidad de la economía regional pone en evidencia que ésta no es ajena a choques de orden social, como el conflicto armado o el narcotráfico, y a otros de orden natural, como el factor climático.

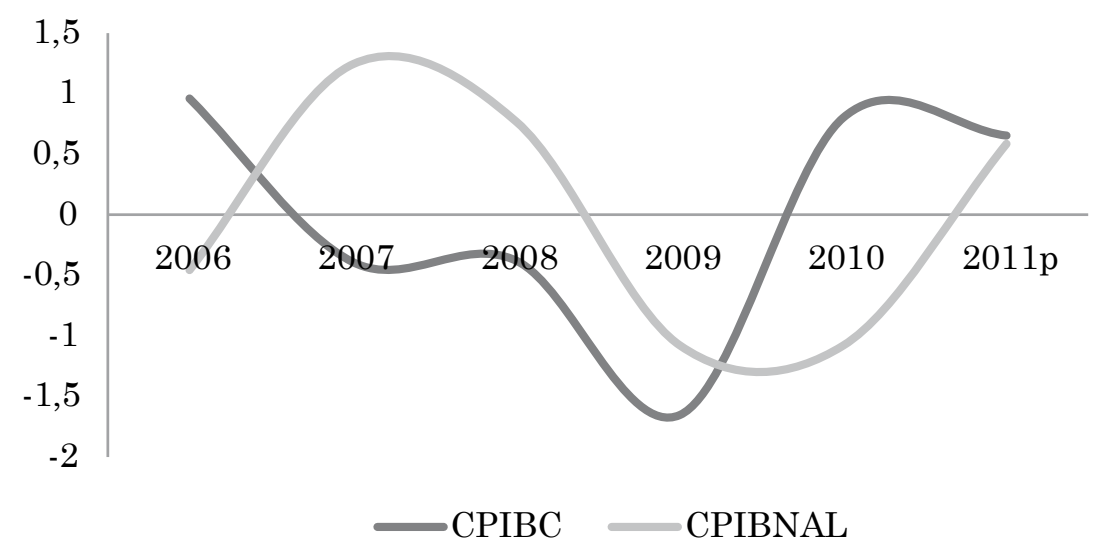

Gráfico 1. Ciclo económico del Cauca y Colombia. Filtro de Hodrick-Prescott normalizado, 2006-2011.

Fuente: elaboración propia a partir de DANE (2007, 2008, 2009, 2010, 2011, 2012).

\footnotetext{
${ }^{4}$ El ciclo económico como es tradición en la literatura económica es determinado a través del Filtro de Hodrick-Prescott. Para poder compararse con otros ciclos, por ejemplo con el nacional, se han normalizado las series. Por tanto, las unidades de medida son desviaciones estándar y no tasas de crecimiento.
} 
Otra característica a resaltar, es que la relación entre expansiones y recesiones es contracíclica entre 2006 y 2008, y procíclica desde 2009. Esto indica que el Cauca muestra comportamientos económicos de corto plazo que no se compaginan al inicio del periodo analizado con los nacionales, pero posteriormente si lo hace. ${ }^{5}$

Frente al crecimiento, el PIB caucano ha mostrado tasas de crecimiento por debajo del nacional al principio y final del periodo analizado, pero en el intermedio las tasas regionales superaron a las nacionales. Como se mencionó anteriormente, en el año 2009 se refleja el impacto de la crisis financiera mundial en la economía nacional, en donde se creció solamente en un $1,65 \%$, mientras que el Cauca mostró una ampliación del 3,04\% en su nivel de actividad económica gracias al fenómeno de las pirámides.

\footnotetext{
${ }^{5}$ En términos precisos, se dice que dos economías son procíclicas cuando la expansión (recesión) de una se compagina con la expansión (recesión) de la otra; y contracíclicas cuando la expansión (recesión) de una se compagina con una recesión (expansión) de la otra. En términos técnicos, esto se mide con la correlación que existe entre ellas. Un signo positivo evidencia comportamientos procíclicos, un signo negativo contra cíclicos, y cero que no guardan ningún tipo de relación. Para este caso, el valor de la correlación fue de 0.32 ; es decir, existen comportamientos procíclicos.
}

Ya para 2010, a pesar del fenómeno de La Niña, que afectó no sólo al departamento sino a todo el país, ${ }^{6}$ se presenta el mayor crecimiento de la economía del Cauca, alcanzándose los 6,72 puntos porcentuales, la cifra más alta alcanzada no sólo del periodo sino en las últimas décadas. A pesar de este buen comportamiento, la participación de la economía caucana en la economía nacional históricamente ha sido muy baja, generalmente ubicándose entre el 1\% y el 2\%, siendo las que más participan Bogotá (25,8\%), Antioquia (13,4\%) y Valle $(9,7 \%)$. No deja de ser paradójico que se experimenten tasas de crecimiento por encima de la nacional pero que la participación del PIB caucano sea tan baja y los niveles de desempleo tan altos (cercanos al 18\%).

Para el periodo de referencia, se encuentra que las más altas participaciones se ubican en el año 2006 (1,43\%) y en 2010 $(1,47 \%)$, y las más bajas se encontraron en el año 2007 (1,37\%) y 2008 (1,36\%). El rezago de la economía caucana obedece, entre otros factores estructurales, a la alta dependencia del sector de servicios, una considerable dependencia del agro y

\footnotetext{
${ }^{6}$ Los sectores que resultaron más afectados en el Cauca fueron: vivienda, la infraestructura hospitalaria $y$ educativa, las vías y el sector agrícola.
} 


\section{$\square$ CAUCA $\square$ COLOMBIA}

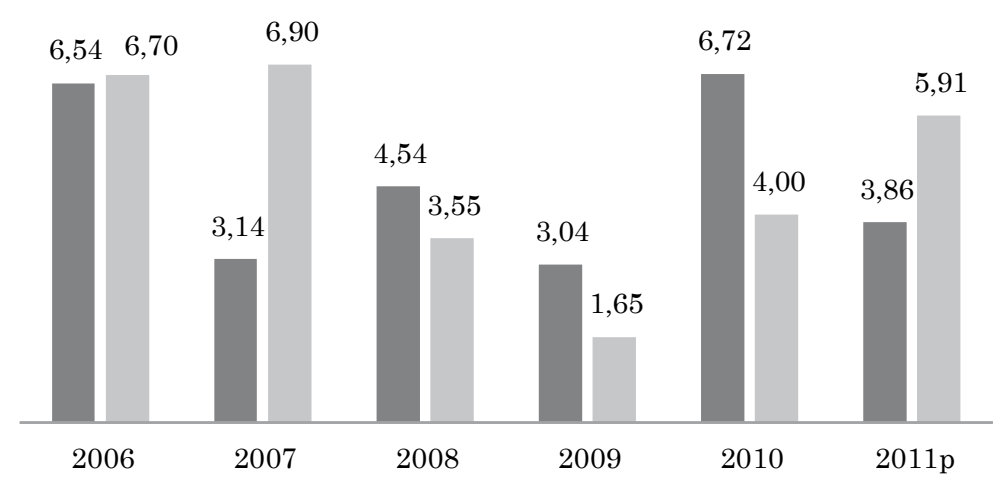

Gráfico 2. Tasas de crecimiento anual del PIB Cauca y Colombia, 2006-2011.

Fuente: elaboración propia a partir de DANE (2007, 2008, 2009, 2010, 2011, 2012).

a los bajos niveles de industrialización. ${ }^{7}$ La baja participación es consistente con

\footnotetext{
${ }^{7}$ A pesar de que el sector industrial ha tenido una participación creciente en el nivel de actividad económica del Cauca en las dos últimas décadas, alcanzando el $20 \%$ del total del PIB, el Cauca aún no se considera un departamento industrializado. Las empresas ubicadas en el norte del departamento producto de la finalizada Ley Páez, a pesar de presentar altos niveles de contratación, productividad y fuertes inversiones en capital físico y tecnologías, son empresas cuyas ganancias migran hacia al Valle y el empleo generado para altos cargos son de personas que residen también en ese departamento. Los empleos de bajo rango pertenecen a caucanos de la zona, pero su impacto económico es mínimo. Para una mayor ampliación de estos aspectos, véase, Gómez (2010).
}

la evolución del PIB per cápita regional. A pesar de que su tasa ha sido creciente, como lo muestra el gráfico 2, llegando a una tasa de crecimiento promedio de $3,8 \%$ para el periodo analizado, inclusive por encima del nacional $(3,5 \%)$, siempre ha sido inferior al PIB per cápita nacional en términos absolutos. Específicamente, la relación generalmente es de dos a uno, es decir, a un colombiano promedio le corresponde a 2010, $\$ 9.333 .00$ del PIB nacional, mientras que a un caucano promedio le corresponde para el mismo periodo, $\$ 4.660 .00 \mathrm{del}$ PIB departamental. 
El PIB per cápita a nivel nacional a 2010 es de $\$ 9,3$ millones; es decir que los caucanos tienen una amplia desventaja frente a colombianos de otras regiones, sobre todo con los habitantes de departamentos que contienen a las grandes capitales. El puesto ocupado es el 25 de los 33 departamentos (incluido Bogotá) que existen en nuestro país. Además, el nivel regional es superado casi por todos sus vecinos, ya que el PIB per cápita medido en millones para el Valle es de $\$ 9,7$; en Tolima de $\$ 7,6$, en Huila de $\$ 7,4$ y en Putumayo $\$ 7,3$, pero no es superado por Nariño $(\$ 3,9)$ y Caquetá $(\$ 3,1)$. El bajo ingreso per cápita del Cauca también se manifiesta por la pobreza del departamento, según el informe realizado por el Departamento Nacional de Planeación (DNP) a 2010, el 64,3\% de los caucanos padece de este problema social y el 35,9 $\%$ vive en extrema pobreza. El informe señala que la gente que es pobre vive con ingresos que no superan los 190 mil pesos, mientras que los que están en la indigencia tienen un ingreso máximo de 78 mil pesos mensuales (DNP, 2011).

Frente a la concentración del ingreso, el coeficiente de Gini ha evolucionado desfavorablemente, pues a inicios del nuevo milenio era de 0,53, y para 2011 es de 0,61. Esto indica que cada vez más los ingresos se están concentrando en una reducida parte de la población y la gran mayoría cada vez se hace más pobre. Finalmente, las necesidades básicas insatisfechas (NBI), de acuerdo al censo de 2005, era de $46,4 \%$; esto indica que casi la mitad de los caucanos tiene insatisfecha alguna necesidad considerada básica, como vivienda, servicios públicos, ingresos o educación.

\section{Dinámica económica por rama de} actividad. La dinámica de la economía del Cauca depende básicamente de cinco grandes ramas de actividad económica, que representan para el periodo analizado generalmente el $75 \%$ de la producción total. De acuerdo con el gráfico 3, las ramas de mayor peso son la de servicios, industrial, financiera, agrícola y comercial; y los de menor proyección son transporte, electricidad, construcción y minas.

Es de destacar que la tendencia del sector agrícola ha sido decreciente bajo el periodo analizado, alcanzando un promedio del 13\%, mientras que un comportamiento contrario ha mostrado el sector servicios, cuyo aporte ha evolucionado favorablemente logrando en promedio 23,2 puntos porcentuales en el último lustro. El sector manufacturero, financiero, al igual que el comercial, han mantenido un comportamiento tendencial más estable frente a los dos anteriores y, en promedio, han logrado una contribución de $17,2 \% ; 14,8 \%$; y $8,7 \%$, respectivamente. 


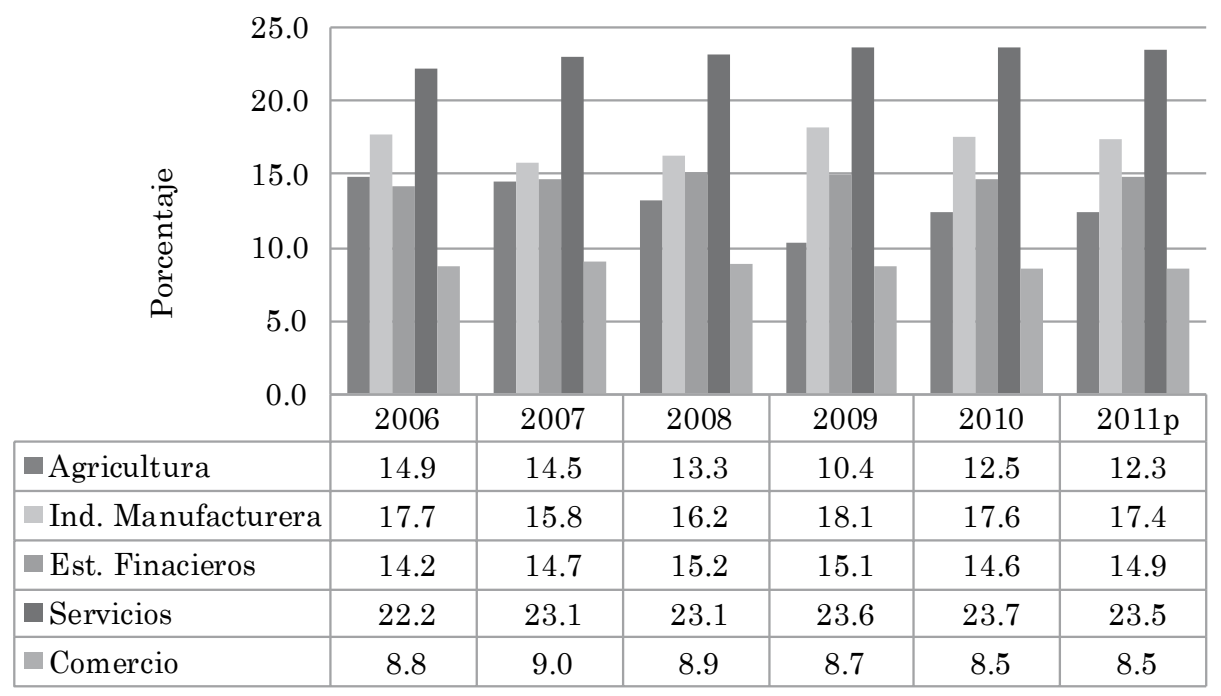

Gráfico 3. Participación por ramas de actividad económica, PIB Cauca, 2006-2011. Fuente: elaboración propia a partir de DANE (2007, 2008, 2009, 2010, 2011, 2012).

Históricamente, el sector agrícola del departamento del Cauca se constituyó en el motor de crecimiento del nivel de actividad económica, debido básicamente a que la diversidad y riqueza de sus suelos, sumado a la variedad de climas, le permitió crear ventajas comparativas frente a otras regiones del país. Las explotaciones tradicionales con tecnologías incipientes, la poca participación de otros sectores, al igual que una economía muy cerrada, caracterizaban esa dependencia. Aunque esto fue cierto hasta hace algún tiempo atrás, lo que muestran las cifras es que esa participación ha venido declinando ostensiblemente desde la mitad del siglo anterior. Entre otras muchas causas que explican este abatimiento figuran las limitaciones de recursos de producción de la economía campesina, la coexistencia de una agricultura plagada de intermediación, la agricultura minifundista de subsistencia en el oriente, centro y sur del departamento, la ganadería extensiva en la Hoya del Patía y la reforestación comercial en zonas de ladera. 
El sector de servicios es una de las ramas de actividad económica que mayor protagonismo ha alcanzado en la dinámica del PIB en el departamento del Cauca en los últimos años, aunque también lo ha sido para Colombia y América Latina. Este sector incluye básicamente actividades, que aunque no producen bienes materiales de forma directa, satisfacen necesidades de la población, tales como educación o salud. De acuerdo con la Cámara de Comercio del Cauca (2009), las empresas del sector salud son las responsables de este positivo jalonamiento del PIB. Las expansiones en la oferta de servicios especializados y de nivel superior se han convertido en un imperativo que busca posicionar a su capital como una ciudad capaz de brindar atención en salud en el suroccidente colombiano.

En el caso del sector industrial, el protagonismo de este sector en la economía caucana ha sido creciente desde la década de los sesentas, alcanzó su esplendor finalizando los noventas y parte del nuevo milenio, pero en los últimos años ha perdido terreno a favor del sector de servicios. De acuerdo a Gómez (2011), en la década de los sesenta hasta antes del nuevo milenio, su participación oscilaba en un $11 \%$, pero en gran parte de esta nueva década su contribución alcanzó los veinticinco puntos porcentuales, es decir más del doble. Sin embargo, después de 2006 , su peso ha sido de alrededor de un $17 \% .^{8}$ La finalización de la Ley Páez trajo consigo que varias empresas migraran de la zona del norte del Cauca, pues los incentivos fiscales sólo se mantenían si hacían parte después de una zona franca.

De otro lado, el sector financiero caucano se caracteriza por ser un sector en permanente superávit, es decir, los montos de ahorro siempre superan a los de inversión. La propensión marginal al ahorro es alta, mientras que la de inversión es baja, y esto ha conllevado a que la demanda efectiva siempre se haya visto lesionada, generando que los niveles de desempleo siempre sean altos (Mendoza y Sarmiento, 2005). De acuerdo con el DANE (2008), el impacto de las pirámides tuvo repercusiones en este sector, ya que las captaciones en el departamento

\footnotetext{
${ }^{8}$ La época dorada del sector industrial caucano obedeció básicamente a la implementación de la Ley Páez. La Ley 218 de 1995, más conocida como la Ley Páez, se decretó por parte del Congreso de la República para otorgar exenciones tributarias por un periodo de diez años a empresas que se establecieran en la región afectada por la avalancha del rio Páez, para así recuperar e impulsar el desarrollo económico en la zona. Para diferentes análisis del impacto de dicha Ley, véase Gómez, Miller y Rivera (2006) y Congreso de la República, Ley 218 de 1995.
} 
del Cauca mostraron una expansión del $2,5 \%$, de los cuales los depósitos de ahorro y los depósitos en cuenta corriente bancaria siguen presentando la mayor participación en el total de captaciones (54,36\% y $26,16 \%$, respectivamente). A su vez, los certificados de depósito a términos crecieron el $13,2 \%$ y participaron con el $19,31 \%$ del total captado en el departamento.

Ya para el sector comercial, de acuerdo con la Cámara de Comercio del Cauca, y en concordancia con lo expresado en la sección anterior, el sector de comercio es el que mayor número de unidades productivas posee. A pesar de los esfuerzos de esta institución por formalizar los establecimientos del sector, la informalidad está muy arraigada, lo que implica alguna debilidad en el escenario inmediato para hacer seguimiento de la actividad comercial.

Sector externo. Como se observa en el gráfico 4, el Cauca se caracteriza por haber tenido unas importaciones mayores que las exportaciones, es decir, es una región que muestra una balanza comercial deficitaria en el periodo analizado.

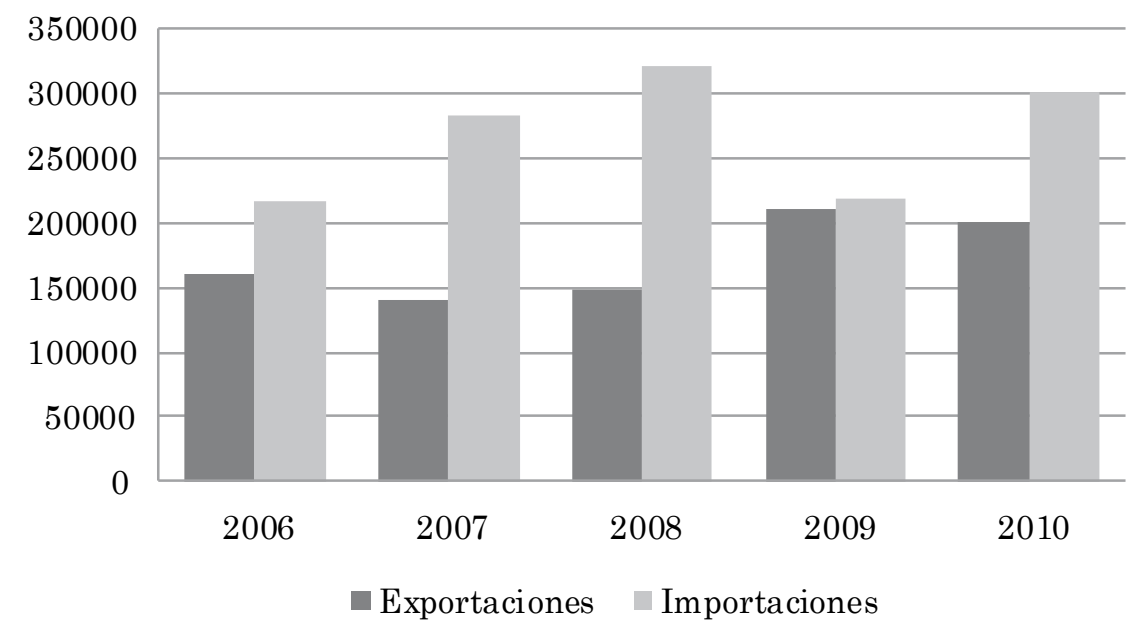

Gráfico 4. Exportaciones e importaciones del Cauca, 2006-2011. Fuente: elaboración propia a partir del DANE (2007, 2008, 2009, 2010, 2011, 2012). 
De manera particular, el sector agrícola ha presentado un decrecimiento continuo en sus niveles de exportación, pues en el 2008 su tasa fue de -36\%; para 2009 registró -16\%; y finalmente, para 2012 se presentó una contracción del $-8.6 \%$. El sector industrial ha tenido un comportamiento más cíclico, ya que a 2007 había experimentado una contracción cercana a los 12 puntos porcentuales; para el siguiente año, una expansión de 6\%; en 2009 un crecimiento del $43 \%$; y para 2010 cerró con una reducción del 5\%. Este comportamiento estuvo directamente influenciado por los vaivenes del mercado internacional, que a su vez estuvo fuertemente afectado por la crisis internacional. Frente a los destinos de las exportaciones, los mejores socios comerciales del Cauca en los últimos años han sido en orden de importancia Ecuador, Perú, Venezuela y Chile.

En promedio, las exportaciones no tradicionales al Ecuador en los últimos 5 años ascendieron a 115 millones de dólares, por tanto, su participación alcanza el $31 \%$. Para Perú y Venezuela, se acerca al 24\%, y para Chile al 20\%. Básicamente lo que se le vende a Ecuador son pañales para bebés; a Venezuela los derivados sulfonados, sales y ésteres etílicos; a Perú depósitos, barriles, tambores y recipientes similares; y finalmente, a Chile azúcares de caña o de remolacha. Del lado de las importaciones, el Cauca, en el último lustro, le compra productos principalmente a los Estados Unidos, México, Corea y China. Tomando el promedio de compras entre 2006 y 2010, la participación de las exportaciones para EE.UU alcanza el 55\%, para México el 18\%, Corea representa el $14 \%$ y China participa con un $12 \%$.

El principal producto importado desde Estados Unidos ha sido la pasta química de madera de coníferas; desde México, los productos enrollados; Corea envía poliacrilatos de sodio o potasio; y desde China, productos laminados planos.

\section{Análisis del mercado laboral}

\section{Estructura y dinámica del mercado de trabajo en Popayán y el Cauca. ${ }^{9}$ De} acuerdo con la información suministrada por la Gran Encuesta Integrada de Hogares (GEIH) del DANE, en el año 2012 la población total para el municipio de Popayán ascendió a 240.220 personas y para el departamento del Cauca a 1.342.658 per-

\footnotetext{
${ }^{9}$ La ciudad de Popayán sólo cuenta con datos del mercado de trabajo desde 2007, año en el cual se implementó por primera vez la Gran Encuesta Integrada de Hogares (GEIH). En la actualidad, Popayán se encuentra incluida en las 24 ciudades donde se realiza la encuesta.
} 
sonas. ${ }^{10}$ Alrededor del $17 \%$ en Popayán y el $21 \%$ en Cauca eran personas que no se encontraban en edad de trabajar y los restantes hacían parte de la Población en Edad de Trabajar $(\mathrm{PET})^{11}$. De ellos, un poco más de 117 mil personas de la capital trabajaban o estaban buscando empleo (Población Económicamente Activa, PEA), mientras que cerca de 597.792 personas del departamento lo estaban haciendo. Es decir, que la capital aportó un $20 \%$ de la mano de obra a la producción de bienes y servicios de todo el departamento, quedando el $80 \%$ restante distribuida en los otros municipios.

La Población Económicamente Inactiva (PEI) fue de 81.438 personas en la ciudad de Popayán y de 462.557 en el departamento del Cauca, es decir, aquellos que no pueden trabajar porque estudian, son amas de casa, rentistas o por incapacidad. La PEA a su vez contiene a los que están desocupados, los cuales llegaron a un poco más de veinte mil personas en Popayán y 68.258 en el Cauca, y a los que están ocupados (un poco más de 96.000 individuos en la capital y 529.534 en el departamento); es decir, que apenas cerca del $18 \%$ de la demanda laboral efectiva de

\footnotetext{
10 El DANE la estima por proyecciones con base en los resultados de los censos de población.

11 De acuerdo con el DANE, en las zonas urbanas se considera a una persona en edad de trabajar si tiene 12 años y más, y en las zonas rurales si tiene 10 años y más.
}

todo el departamento está ubicada en la capital. Del total de ocupados en la ciudad capital, 47.380 manifestaron estar inconformes, ya sea por el número de horas que trabajan, por los ingresos que reciben o por la incompatibilidad de sus competencias, mientras que en el departamento 272.055 personas manifestaron las mismas inconformidades. Quienes manifestaron lo mismo pero además hicieron alguna gestión para cambiar de trabajo y estaban disponibles para aceptar una mejor oferta laboral (subempleo objetivo), suman 15.928 trabajadores en la ciudad de Popayán y 74.235 en el Cauca.

De acuerdo con el gráfico, la PET en Popayán y Cauca ha experimentado un patrón de crecimiento sostenido y similar al experimentado por el total de las 23 ciudades principales durante el periodo considerado. En efecto, desde 2007 a 2012, la PET creció un $2,59 \%$ en la capital y un $2,79 \%$ en el departamento, el cual, frente al agregado nacional, muestra como la PET tuvo también un comportamiento tendencial positivo (aunque un poco inferior) de $2,15 \%$ en el periodo analizado.

Este comportamiento obedece a la evolución de la estructura demográfica del departamento y del país en los últimos años, que muestra que si la PET está creciendo porcentualmente, la población menor de diez años está experimentando proporcionalmente un 
decrecimiento sostenido en este periodo. Por tanto, es posible concluir a priori que posiblemente en Popayán y en el Cauca el número de personas que pueden trabajar está siendo cada vez mayor pero el mercado labo- ral, como se verá más adelante, no ha podido responder a esta alza de la PET, principalmente en la capital del departamento, en donde la tasa de desempleo se ha mantenido en porcentajes comparativamente más altos.

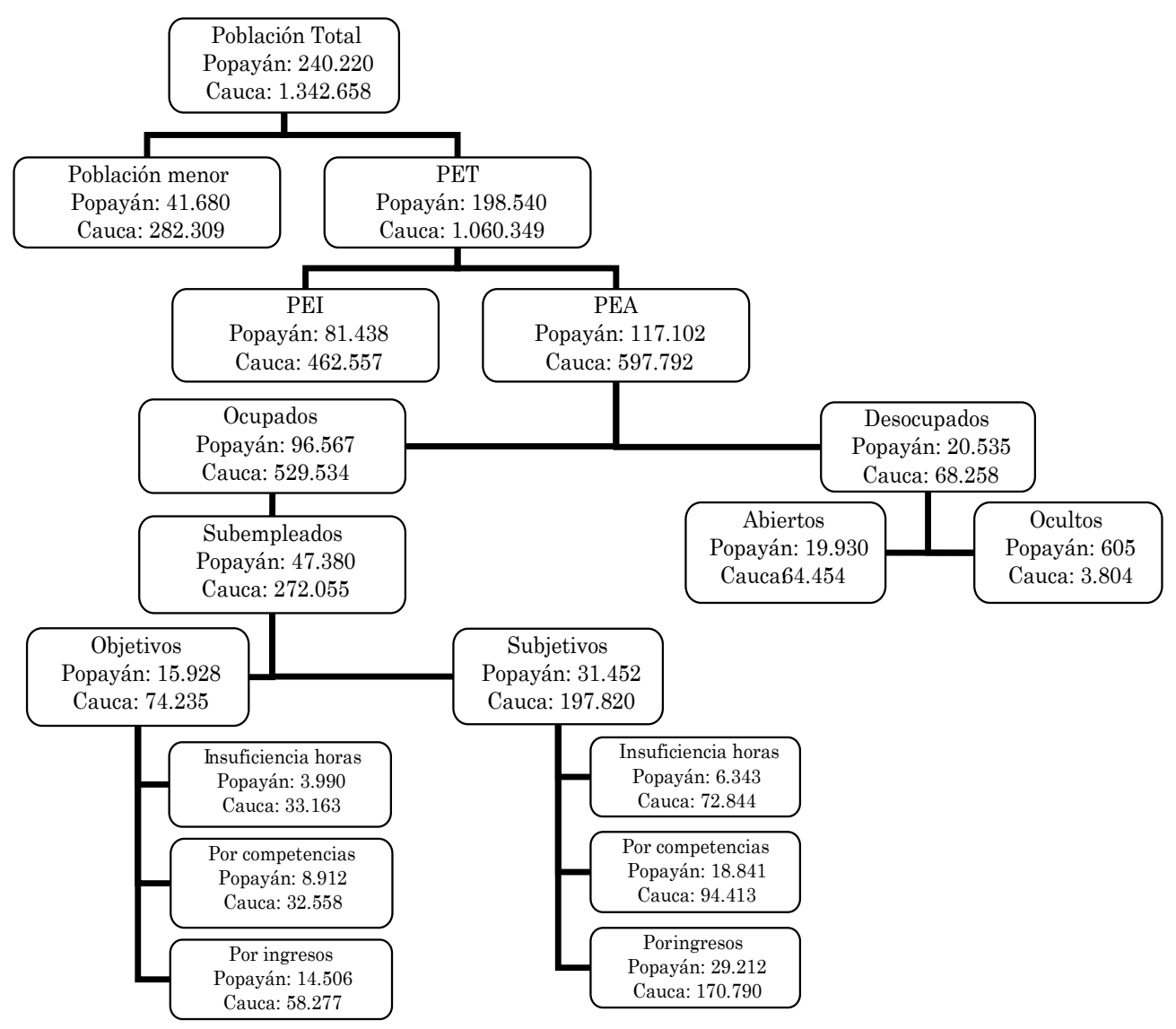

Gráfico 5. Estructura de la fuerza laboral, 2012.

Fuente: elaboración propia a partir de GEIH-DANE (2012). 
La PET mostró una tendencia creciente en el periodo analizado para ambos sexos y ambas desagregaciones geográficas. Sin embargo, hay cierta diferencia en la composición porcentual por sexo cuando se observan los datos para Popayán y para el Cauca. En promedio, para los años de 2008 a 2012, de la población total de la ciudad que por su edad puede laborar, el $47 \%$ eran hombres y el $53 \%$ eran mujeres, mientras que para el departamento el porcentaje fue de $50 \%$ para los dos sexos. La diferencia entre hombres y mujeres es notoria para la ciudad de Popayán, ya que llega casi a las doce mil mujeres más, diferencia que se mantuvo a lo largo de los cinco años analizados.

Las tasas de crecimiento de la PET por sexo fueron mayores para el caso de los hombres que para las mujeres, siendo aproximadamente de $6,21 \%$ y $5,45 \%$, respectivamente, para la ciudad, y de $6,62 \%$ y $4,64 \%$ para el departamento. Esto estaría indicando que de mantenerse esas tendencias en las tasas de crecimiento, la brecha de la PET por sexo para Popayán y el Cauca tendería a expandirse, con más rapidez en el caso del departamento. Este comportamiento plantea un interesante tema de investigación para tratar de explicar por qué dicho diferencial es comparativamente más marcado en la ciudad de Popayán que en el agregado departamental, y qué implicaciones tiene esto para la política pública local de creación de empleo en la ciudad, la cual sin duda debe tener un enfoque diferencial teniendo de presente este tipo de resultados.

A lo anterior se añade que posiblemente las mujeres en Popayán y en el Cauca sigan la tendencia nacional de ser las protagonistas de una fuerte discriminación laboral. En efecto, Galvis (2010) señala que existe en nuestro país diferenciales de salarios positivos a favor de los hombres y que las brechas salariales no están explicadas principalmente por los atributos observables de los individuos, por lo cual ello implica la posible existencia de discriminación por género.

Frente a la población económicamente activa PEA, se observa que para Popayán su comportamiento ha sido muy estable en el periodo seleccionado, ya que siempre ha oscilado en un 59\%. A nivel de las 23 ciudades, el comportamiento ha sido un poco más pronunciado, alcanzando un $64,4 \%$ en promedio. Frente a la población inactiva PEI, la capital del Cauca muestra un comportamiento escasamente creciente $(0,24 \%)$, mientras que para el resto de ciudades se manifiesta una tendencia decreciente $(-13,8 \%)$.

El gráfico 6 indica que Popayán y el Cauca tuvieron un comportamiento diferente a 


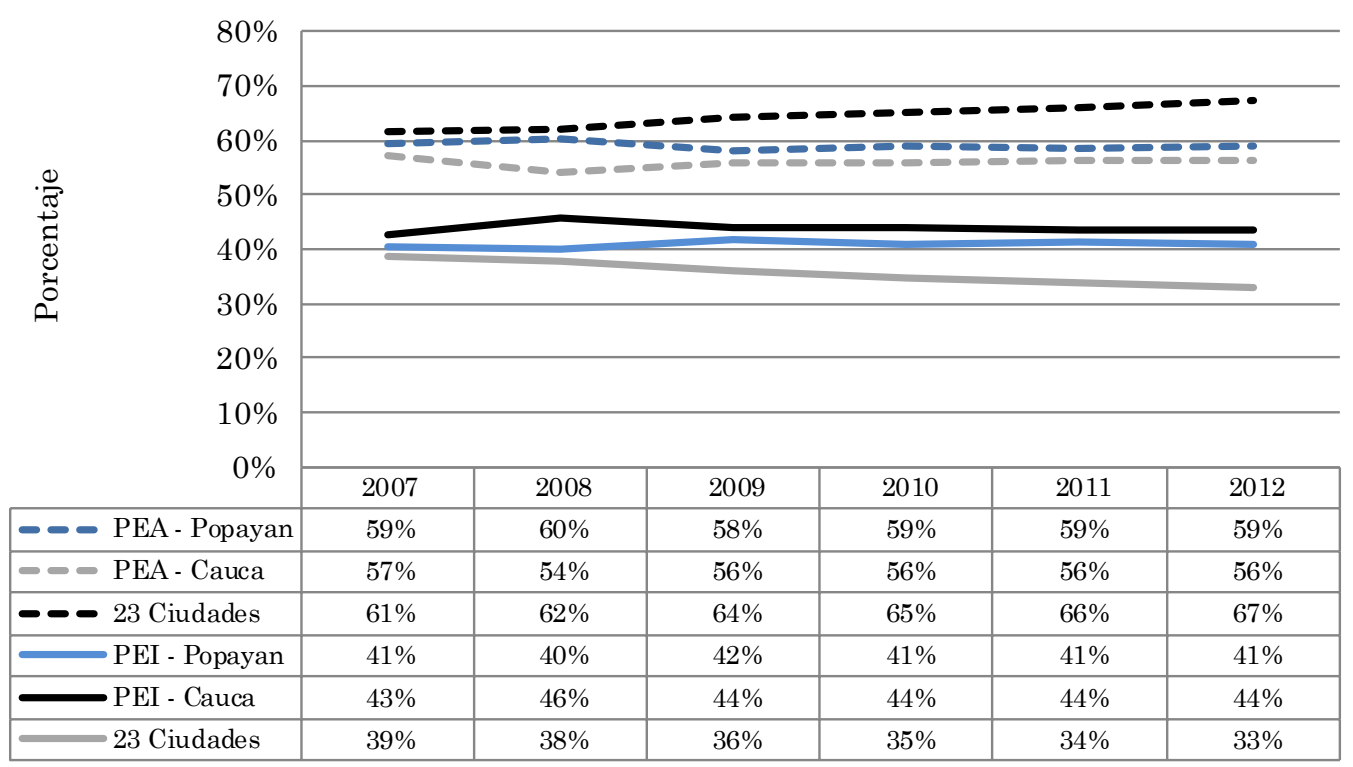

Gráfico 6. Composición porcentual de la PET, según la PEA y la PEI. Cauca, Popayán y 23 Ciudades. 2007 - 2012. Fuente: elaboración propia a partir de DANE (2007, 2008, 2009, 2010, 2011, 2012).

lo que sucedió a nivel de las 23 ciudades. En efecto, el porcentaje de las personas en edad de trabajar que trabajan o están buscando empleo (PEA) fue superior para el agregado de las 23 ciudades que para Popayán y el departamento del Cauca, mientras que el porcentaje de aquellas que no trabajaron o necesitan hacerlo (PEI) fue más alto para el Cauca y Popayán. ${ }^{12}$

\footnotetext{
${ }^{12}$ Las razones por las cuales se presenta este fenómeno se desconocen, se hacen necesarias futuras investigaciones para poder dar cuenta de ello.
}

La tendencia de las series también indica que mientras para el agregado de las ciudades y áreas metropolitanas el porcentaje de la PEA aumentó a razón de 9,39\% en el periodo de referencia, para la ciudad de Popayán y el departamento del Cauca el porcentaje de esta población disminuyó en $0,65 \%$ y $1,67 \%$, respectivamente. Es decir, mientras para el resto del país hay un patrón de aumento de la oferta laboral en comparación con la población inactiva, en el departamento del Cauca y la ciudad de Popayán el patrón es contrario. 
La PEA desagregada por sexo para los años de 2008 a 2012, mostró que en la ciudad de Popayán hubo más hombres trabajando o buscando trabajo que mujeres en un porcentaje promedio de $53 \%$ y $47 \%$, respectivamente. Patrón que tendió a acentuarse a lo largo de los años, pues la tasa de crecimiento de la PEA para los hombres fue de $6 \%$, mientras que para las mujeres fue del 1\%. Para el caso del departamento del Cauca, la composición porcentual de la PEA por sexo mostró un patrón mucho más marcado a favor de los hombres, siendo en promedio de $63 \%$ para estos y de apenas $37 \%$ para las mujeres. No obstante, la tasa de crecimiento entre 2008 y 2012 fue mucho mayor para las mujeres del departamento que trabajan o están buscando trabajo, alcanzando el $15,5 \%$, mientras que la de los varones fue de $6,5 \%$; es decir, que de mantenerse esta tendencia, la brecha de participación entre ambos sexos en la PEA tendería a cerrarse, contrario a lo que está sucediendo en la capital.

Los resultados anteriores permiten también concluir que, de acuerdo con los indicadores por sexo para la PET que fueron hallados para la ciudad de Popayán en los que la participación porcentual de las mujeres era mayor, hay una clara tendencia a que las mujeres tiendan a inactivarse económicamente mucho más que los hombres. Detrás de éste fenómeno, pueden existir diferentes razones asociadas, ya sea con discriminación laboral hacia las mujeres, economía reproductiva o del cuidado, o desmotivación para salir a buscar trabajo; hipótesis cuya comprobación desbordarían el alcance de este documento pero que sugieren futuros temas de investigación para el departamento del Cauca alrededor del tema del mercado laboral con enfoque de género.

Frente a la TGP (oferta de trabajo) y la TO (demanda de trabajo) se encontró que la brecha existente entre ellas fue más amplia para Popayán que para el Cauca en el periodo analizado. En efecto, el mercado de trabajo local encontró siempre una oferta laboral superior a la demanda (11,3\% de diferencia en promedio para Popayán y 6,0\% para el Cauca), aunque con tendencias distintas durante los seis años de referencia pues se redujo apenas 1,3 puntos porcentuales para la capital y se incrementó en 1,1 puntos porcentuales en el departamento.

Es de esperarse, además, de acuerdo con los resultados anteriores, que la TGP desagregada por sexo muestre un patrón en el cual el porcentaje de hombres que están dispuestos a ofrecer su fuerza laboral sea mayor que en el caso de las mujeres. 


\section{Popayán}

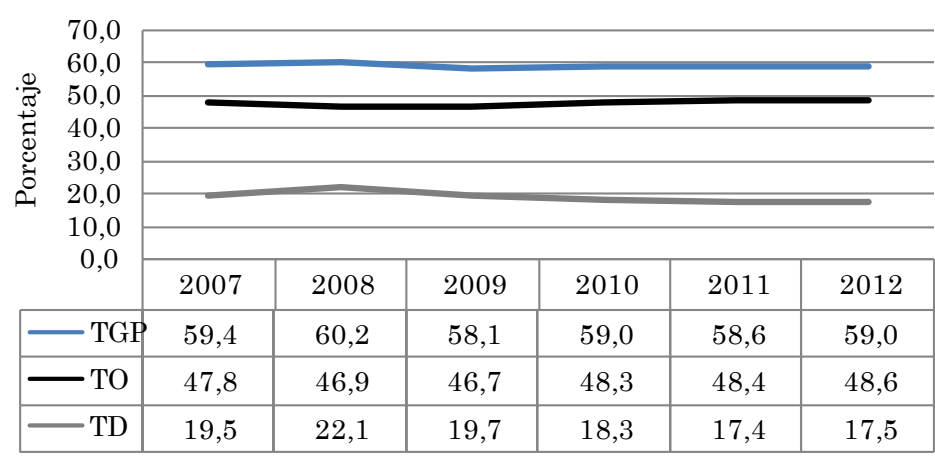

\section{Cauca}

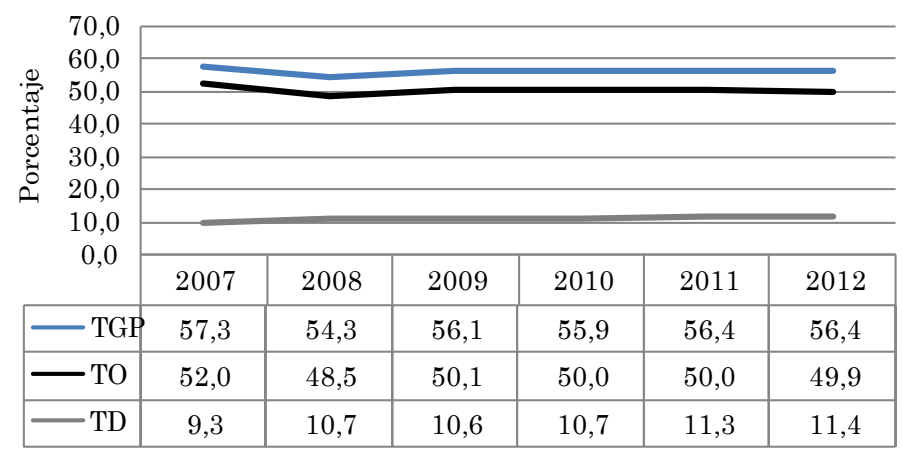

Gráfico 7. Tasa de ocupación, desocupación y global de participación. Popayán y Cauca. 2007 - 2012.

Fuente: elaboración propia a partir de DANE (2007, 2008, 2009, 2010, 2011, 2012).

Es así que en promedio la TGP para los hombres fue de $67 \%$ mientras que para las mujeres fue de $52 \%$ en la ciudad de Popayán durante los años 2008 a 2012; diferencia aún más marcada en el departamento, ya que para los primeros fue en promedio de $71 \%$, en tanto que para las segundas fue de $41 \%$. De manera similar y derivado del patrón de la TGP por sexo, la TO muestra una brecha entre hombres y mujeres a favor de los ellos tanto en la capital como en el departamento. 
Desocupación o desempleo. El desequilibrio persistente que existe entre la oferta y la demanda de trabajo se traduce en desempleo. Para Popayán, la tasa de desempleo (TD) ha sido de las más altas del país, alcanzando cifras que sobrepasan los 20 puntos porcentuales, como sucedió en el año $2008(22,1 \%)$. A pesar de que ha tenido un comportamiento cíclico, los niveles alcanzados son muy altos, llegando a ser en este lustro una de las ciudades con mayor número de personas que no tienen empleo en todo el país (19,1\% en promedio).

Si bien la TD en la ciudad ha venido disminuyendo desde 2009, logrando unos niveles del $17,5 \%$ en 2012 , frente a las 23 ciudades, este indicador del mercado laboral para Popayán se mantuvo muy por encima del promedio, que fue de $11,8 \%$, aunque por debajo de Pereira únicamente para el año 2009, que mostró una TD de 20,3\%. De acuerdo con el DANE, en el trimestre que va de octubre a diciembre de 2012 , Popayán alcanzó el segundo desempleo más alto de las ciudades más importantes del país $(15,4 \%)$, después de Pereira $(15,5 \%)$ y muy por encima de Bogotá $(8,5 \%)$, Medellín (11,1\%) y Cali (13,2\%).

En el departamento del Cauca, el indicador de desempleo es comparativamente mucho más bajo que en su capital, el cual mostró un promedio de 10,7\% a pesar del aumento que ha venido teniendo, pues pasó de registrar un 9,3\% en 2007 a un 11,4\% de desempleados en 2012. La brecha existente entre la capital y el departamento está indicando que existen otros municipios dentro del departamento que tienen la capacidad de generar más oportunidades de empleo que la capital, posiblemente aquellos donde hay una importante concentración de población, como Santander de Quilichao, Puerto Tejada, El Tambo y Bolívar.

La tasa de desempleo abierto (TDA), en promedio, alcanzó el 18,5\%, y la oculta (TDO) $0,56 \%$ en Popayán, mientras que para el departamento la TDA alcanzó el $9,8 \%$ y la TDO el $0,8 \%{ }^{13}$. Se observa una relación directa entre los niveles de desempleo y el nivel de presión que ejercen las personas desempleadas sobre el mercado de trabajo, es decir, que cuando el nivel de desempleo resulta mayor, así mismo las personas están presionando más fuerte las vacantes (como en la ciudad de Popayán), mientras que cuando el desempleo es menor, la presión resulta igualmente menor.

\footnotetext{
${ }_{13}$ El desempleo abierto hace referencia al número de personas que no tenían empleo en la semana de referencia, pero hicieron diligencias en el último mes para conseguirlo y tenían disponibilidad de trabajar de manera inmediata. El desempleo oculto, hace referencia al número de personas que no tenían empleo en la semana de referencia, no hicieron diligencias en el último mes para conseguirlo pero sí en los 12 últimos meses, tenían una razón válida de desaliento y tenían disponibilidad de trabajar.
} 
Adicionalmente, dados los bajos niveles de la TDO, hay muy pocas personas que se están desmotivando tanto en la capital como en el departamento para salir a buscar trabajo.
Desempleo según sexo. El desempleo por sexo en Popayán y en el Cauca fue mayor para las mujeres que para los hombres en el periodo de referencia, a pesar de que la PET y la PEA mostraron un patrón

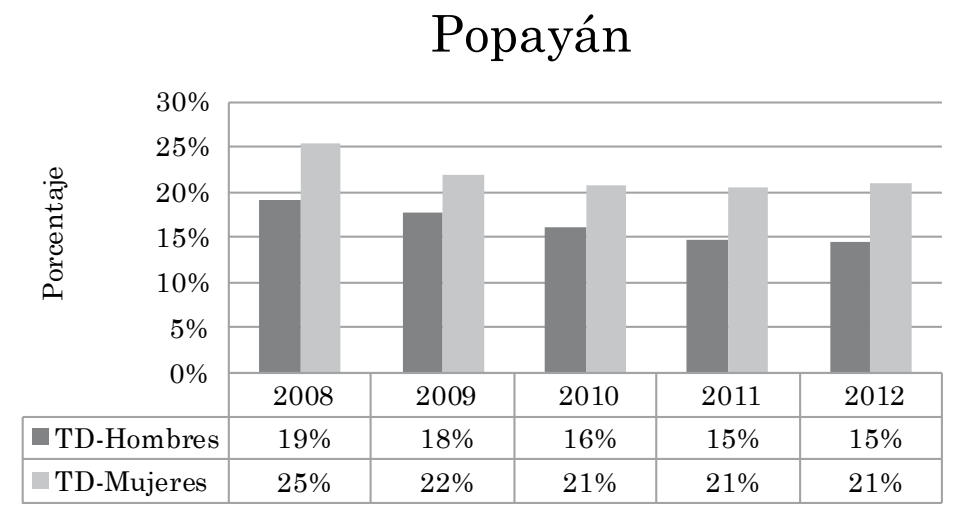

\section{Cauca}

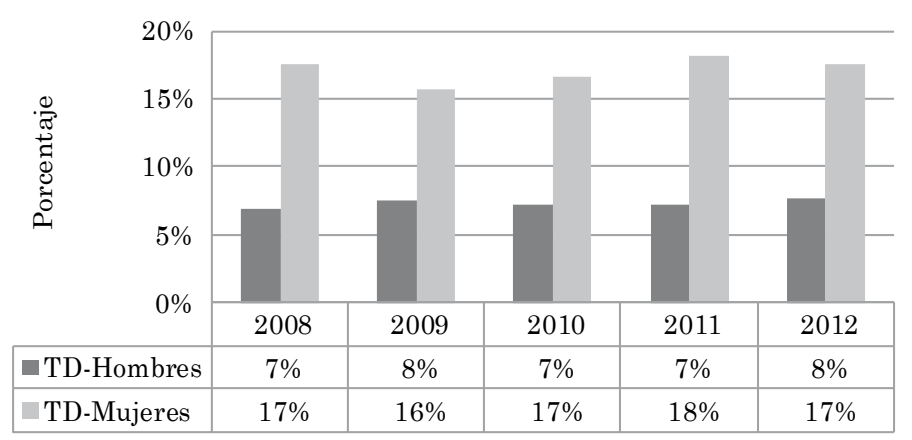

Gráfico 8. Tasa de desempleo (TD) por sexo. Popayán y Cauca. 2008-2012.

Fuente: elaboración propia a partir de DANE (2007, 2008, 2009, 2010, 2011, 2012). 
contrario. De acuerdo con el gráfico 8, la evolución entre 2008 y 2012 presentó una tendencia decreciente tanto para hombres como para mujeres en la capital, aunque fue más marcada para los primeros, cuya TD bajó de $19 \%$ a $15 \%$, que para las segundas, cuya TD bajó de $25 \%$ a $21 \%$. Es decir, que de mantenerse este ritmo de descenso en la TD para ambos sexos, la brecha tendería a aumentarse en la ciudad de Popayán.

Para el departamento del Cauca, la brecha entre hombres y mujeres desempleados fue mucho más marcada que en la capital, la cual alcanzó una diferencia de hasta 11 puntos porcentuales tanto en el año 2008 como en el 2011, además, con cierta tendencia a mantenerse inalterada. Es evidente, además, que las altas TD de las mujeres caucanas, cercanas al $17 \%$ y $18 \%$, son las que jalonan a que la TD general para el departamento se mantenga en niveles cercanos al 11\%. De manera tal que, una política pública en el departamento encaminada a disminuir las altas tasas de desempleo en las mujeres impactaría fuertemente las altas tasas de desempleo de la región.

Como elemento adicional, la tasa de desempleo trimestral en las mujeres tiene un comportamiento mucho más volátil que la de los hombres. Esto implicaría que cualquier choque externo tendría una repercusión mucho más amplia (ya sea de forma positiva o negativa) en el comportamiento del empleo (o desempleo) para las mujeres que para los hombres. Por tanto, cualquier política encaminada a subsanar el problema debe realizarse contemplando dicha volatilidad.

Tasa de desocupación (TD) juvenil. La TD juvenil, que comprende el porcentaje de las personas con edades entre los 14 y los 26 años desempleadas, se ubicó en un promedio de 35\% para la ciudad de Popayán y de 20\% para el departamento del Cauca; mucho más alto que cuando se observa la TD incluyendo a todas las personas. En el gráfico 11 , se muestra que el desempleo a nivel local de los hombres y mujeres entre los 14 y 26 años fue extremadamente alto, mucho más alto para la ciudad de Popayán que para el Cauca. En el caso de los varones, el promedio entre los años 2008 a 2012 se encontró en $31 \%$ y para las mujeres en $39 \%$, además, con la tendencia a que la brecha se amplíe puesto que el desempleo juvenil para los hombres disminuyó más rápido que el de las mujeres.

En el departamento, si bien la TD juvenil es comparativamente menor que en la capital, también presentó niveles relativamente altos con promedios de $14 \%$ y $31 \%$ en los hombres y en las mujeres, respectivamente. Se observa además que este indicador creció de $31 \%$ a $35 \%$ para las mujeres, mien- 

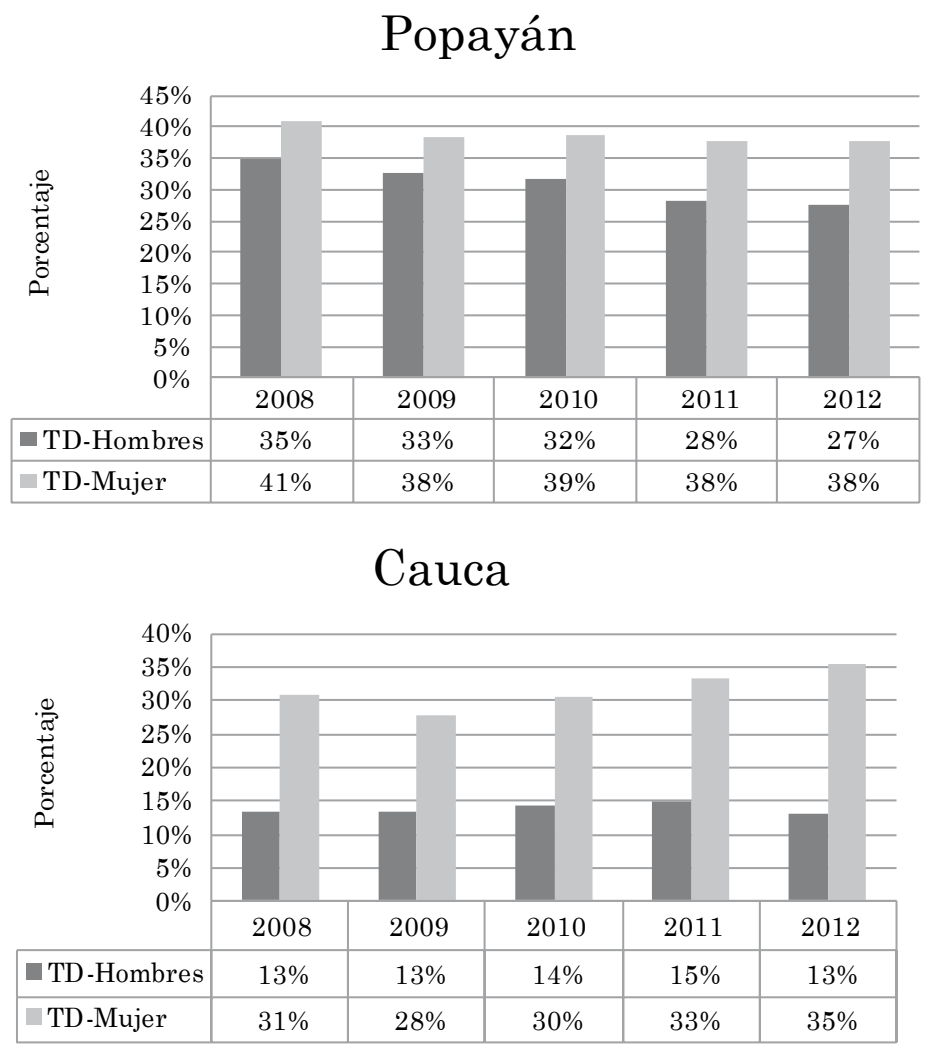

Gráfico 9. Desempleo (TD) juvenil por sexo. Popayán y Cauca. 2008 - 2012.

Fuente: elaboración propia a partir de DANE (2007, 2008, 2009, 2010, 2011, 2012).

tras que para los hombres se mantuvo más o menos estable. Luego en el departamento, la brecha entre los dos sexos de la TD juvenil, además de ser comparativamente alta, también tendió a ampliarse en detrimento de las mujeres.
Adicionalmente, en el 2012, del total de jóvenes que vivían en la ciudad de Popayán y que estaban desempleados, el $71,63 \%$ no se encontraba estudiando, y de acuerdo con el nivel de estudios alcanzado, el 48,41\% era bachiller y cerca de la quinta parte $(20,16 \%)$ 
era técnico o tecnólogo. En el departamento del Cauca, el 82,46\% de los jóvenes desempleados no asistían a un centro educativo, el $51,24 \%$ era bachiller y un poco más de la décima parte (13,34\%) era técnico o tecnólogo. Es decir, que los altos índices de desempleo juvenil, están asociados a altos índices de jóvenes que infortunadamente no estudian y cuyo nivel educativo predominante es el bachillerato; asociación que es mucho más marcada en el departamento del Cauca que en su capital.

\section{Tasa de subempleo}

Subjetivo. De acuerdo con el DANE, el subempleo subjetivo se refiere al simple deseo manifestado por el trabajador de mejorar sus ingresos, incrementar el número de horas trabajadas o tener una labor más propia de sus competencias. ${ }^{14}$ La tasa total de subempleo subjetivo fue decreciente para Po-

\footnotetext{
14 El subempleo subjetivo puede manifestarse de tres formas. Subempleo por insuficiencia de horas, es decir, ocupados que desean trabajar más horas ya sea en su empleo principal o secundario y tienen una jornada inferior a 48 horas semanales. Subempleo por competencias, es decir, puede incluir todas las personas que trabajan y que durante el período de referencia desean cambiar su situación de empleo actual para utilizar mejor sus competencias profesionales. Y finalmente, el subempleo por ingresos, el cual puede incluir todas las personas ocupadas que, durante el período de referencia, deseaban cambiar su situación actual de empleo con objeto de mejorar sus ingresos limitados.
}

payán y el departamento del Cauca en los últimos seis años. De $45 \%$ en 2007 , se pasó a $27 \%$ en 2012 , es decir, que se presentó una caída cercana al $41 \%$, mientras que para el departamento fue cercana al 29,6\%. Este comportamiento mostró que para el mercado laboral de la ciudad y el departamento, cada vez menos personas de las que están empleadas declaran querer mejorar su empleo, lo cual puede tener dos lecturas: por un lado que exista una mejor calidad en él, o por el contrario, el alto desempleo los conforma con el empleo que tienen. En el departamento ocurrió el fenómeno de reducción relativo del empleo subjetivo en menor proporción.

En términos específicos, todos los tipos de subempleos mostraron tendencias decrecientes, pero la gran mayoría manifestaron su descontento con los ingresos recibidos, las personas ocupadas declararon incompatibilidad de competencias en menor proporción y lo que menos expresaron fue el descontento por las horas trabajadas. Hubo un incremento significativo entre el 2008 y 2010 del porcentaje de personas que se encontraban subempleadas por empleo inadecuado en competencias, incrementándose en alrededor de ocho puntos porcentuales en la ciudad y seis puntos en el departamento, lo que mostró la creciente diferencia entre el tipo de demanda y el tipo de oferta laboral que se presentó en la capital y en el departamento caucano. 
Objetivo. El subempleo objetivo comprende a quienes tienen el deseo, pero además han hecho una gestión para materializar su aspiración y están disponibles para efectuar el cambio. Al igual que el empleo subjetivo, éste se divide en subempleo objetivo por horas, competencias e ingresos.

La tasa total de subempleo objetivo en Popayán y el Cauca fue menor que la tasa total de subempleo subjetivo, no obstante, para la ciudad de Popayán ambas tasas mostraron una tendencia decreciente en el periodo considerado. Desde el 2007 al 2012 , su contracción fue del $16,4 \%$ al $13,6 \%$, mientras que en el departamento aumentó al pasar de $10,8 \%$ en el 2008 al $12,4 \%$ en el 2012. En términos específicos, todos los tipos de subempleos mostraron tendencias decrecientes en la ciudad del Popayán, a excepción de la incompatibilidad por competencias. En tanto que en el departamento los tipos de subempleo se mantuvieron alrededor del 5,3\% por horas, $5,7 \%$ por competencias y $9,4 \%$ por ingresos, sin mayores variaciones.

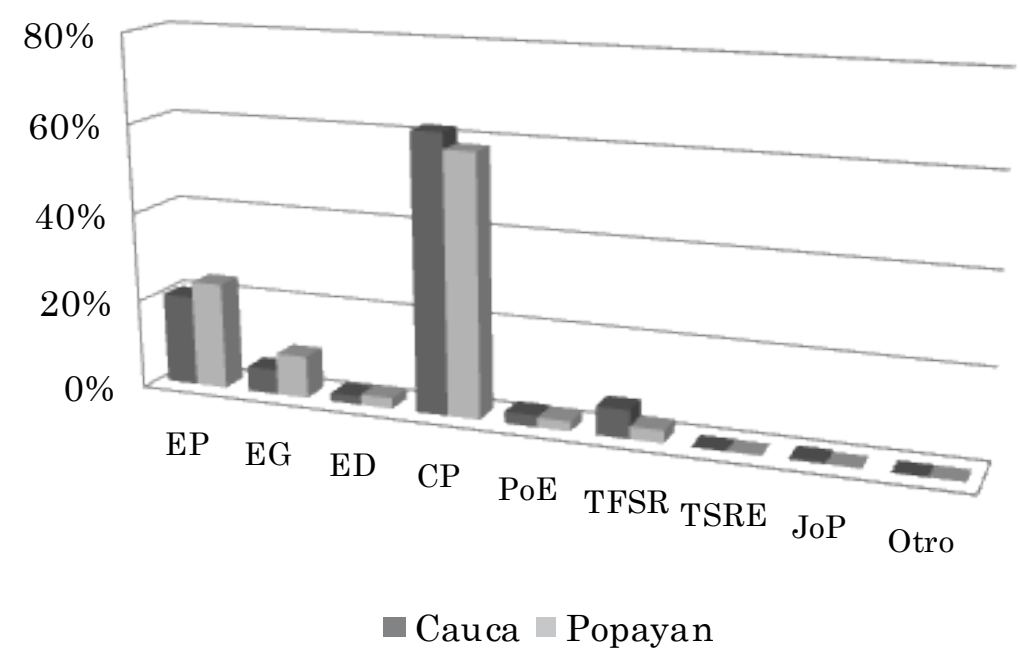

Gráfico 10. Porcentaje ocupados por posición ocupacional. Popayán y Cauca. 2012.

Fuente: elaboración Propia a partir de DANE (2007, 2008, 2009, 2010, 2011, 2012).

EP: empleado particular; EG: empleado del gobierno; ED: empleado doméstico; CP: cuenta propia; PoE: patrón o empleador; TFSR: trabajo familiar sin remuneración; TSRE: trabajo sin remuneración en otras empresas; JoP: jornalero o peón. 


\section{Ocupados por posición ocupacio-} nal. Como lo muestran las cifras, la gran mayoría de las personas ocupadas en Popayán y en el Cauca, son por cuenta propia. Es decir, alrededor del 58,5\% de las personas que tenían empleo en la ciudad y el $62,1 \%$ en el departamento laboraban por su cuenta en el 2012. De forma lejana, alrededor del $24,0 \%$ en la ciudad y $20,4 \%$ en el departamento eran empleados particulares y un 9,5\% eran empleados del gobierno en Popayán, mientras que un 5,7\% lo eran en el Cauca.

La situación no podría ser más preocupante ya que los trabajadores por cuenta propia se caracterizan generalmente por tener empleos inestables que dependen exclusivamente de la demanda del día a día y, además, no realizan aportes a salud, pensiones, cesantías y riesgos profesionales. Esto deviene en una calidad de vida deficiente pues no se procuran ingresos estables ni en el corto ni en el largo plazo.

Ocupados por rama de actividad económica. Con respecto a la actividad económica, el sector de servicios y el sector comercial fueron donde los payaneses encontraron sus mayores posibilidades de emplearse. Es así que, en el 2012, el primero representó el $25,1 \%$ y el segun- do el $21,3 \%$ del total de los empleados de la ciudad. En otras palabras, entre ellos dos consolidaron cerca de la mitad del empleo en la ciudad. Otros sectores, como la industria manufacturera $(15,5 \%)$, la construcción $(11,8 \%)$ y el suministro de energía (10,2\%), aportaron la demanda efectiva de la mano de obra.

Llama la atención que al observar los ocupados por rama de actividad para el departamento del Cauca, el mayor porcentaje se lo llevó el sector de transporte, almacenamiento y comunicaciones con el $37,0 \%$, representado especialmente por el transporte por vía acuática (División 61 de la CIIU Rev.3 A.C.); el resto de sectores exhibieron un patrón parecido al de la ciudad en el que los servicios y el comercio acogieron el $17,5 \%$ y el $12,1 \%$, de la mano de obra del departamento, respectivamente.

Al observar las cifras se nota un patrón muy similar tanto para la ciudad como para el departamento con una clara predominancia masculina o femenina en algunas actividades económicas. Tal es el caso de las actividades inmobiliarias; servicios comunales, sociales y personales; y transporte, almacenamiento y comunicaciones, en las cuales hubo un porcentaje relativamente más alto de hombres que 
de mujeres empleados. Mientras que las actividades de comercio, hoteles y restaurantes, al igual que la construcción, presentaron una prevalencia a emplear más mujeres que hombres (en este sentido debe recordarse que el sector de la construcción abarca también los empleos generados en constructoras e inmobiliarias en actividades relacionadas con la comercialización de bienes raíces). En el resto de actividades, tales como la industria manufacturera, explotación de minas y canteras, y suministro de gas y electricidad y agua la participación por sexo es muy igualitaria. Vale la pena sugerir al respecto un estudio que indague este patrón y proponga alternativas de generación de oportunidades de empleo.

Informalidad. La informalidad es un tema que aún no genera consenso en su definición y por tanto en su medición. A nivel general existen dos definiciones: la sugerida por el DANE y la considerada por otras instituciones, como el Ministerio de Trabajo, conocida como la definición "legalista". Para el DANE son trabajadores informales, los trabajadores familiares sin remuneración, trabajadores por cuenta propia no profesionales ni técnicos, empleados del servicio doméstico, empleados y patrones de empresas del sector privado de hasta diez trabajadores.
En el caso de la segunda, la informalidad está ligada al no pago de seguridad social (pensión) por parte del trabajador.

Debido a que Popayán recientemente fue vinculada a la GEIH realizada por el DANE dentro de las 23 ciudades más importantes, las investigaciones sobre la informalidad aún están pendientes de realizarse. No obstante, tomando la definición "legalista", algunos datos sobre los beneficios a los que debería tener acceso cualquier trabajador(a) son bastante dicientes del rezago del departamento del Cauca y la ciudad de Popayán en términos de la formalización del trabajo. Fenómeno que también aqueja a todo el país, pero que es más grave en la población caucana y payanesa. Si bien, los porcentajes de personas que cotizan a salud son bastante altos, cerca de la tercera parte de ellos lo hacen en el régimen subsidiado. En tanto que quienes cotizan a pensiones, están afiliados a riesgos profesionales o a cajas de compensación familiar son muchos menos con respecto al agregado de las 23 ciudades, situación más preocupante en el departamento.

Existen otros estudios que han realizado instituciones del orden local tales como el Plan de Ordenamiento Territorial o el Plan Local de Empleo, pero ninguno de 
ellos presenta análisis o cifras específicas. Tan sólo existe información de la informalidad en el sector comercial. El único estudio que muestra cifras concretas para Popayán es el realizado por Galvis y Meisel (2012), el cual pone de manifiesto que el porcentaje de personas ocupadas que laboran como informales es del $71,70 \%$ para la definición legalista y del $61,76 \%$ para la definición del DANE. Cifras muy similares a las encontradas en las principales ciudades de la costa Caribe, y superadas por otras como Quibdó, Pasto y Florencia. Además, estima que la probabilidad de estar empleado en el sector informal para Popayán es del 77\%, y asimismo, que existe una relación directa entre los niveles de pobreza y la informalidad.

\section{Programas de empleo ${ }^{15}$}

En el departamento del Cauca, la Caja de Compensación Familiar Comfacauca tiene varios programas enfocados a la generación y mejoramiento del empleo en la región, estos son: el subsidio al desempleo (Fonede) y los programas de capacitación y crédito.

${ }^{15}$ La información presentada en este capítulo es tomada directamente de la página web de Comfacauca (2011).
Fonede es un subsidio que se otorga una sola vez a personas que hayan perdido su empleo. Esta ayuda tiene un valor de $\$ 884.250$ pesos, y se pagan en seis (6) cuotas iguales de $\$ 147.375$ pesos cada una, representadas en bonos de alimentos, de salud y/o educación, a su elección; es decir que no se entrega dinero en efectivo.

Para el año 2011, Comfacauca asignó un total de 1.280 subsidios al desempleo, donde 601 fueron para mujeres y 679 fueron para hombres. El mayor número de subsidios asignados se encuentra en el rango de edad de entre 30 y 34 años, donde 144 fueron para mujeres y 136 para hombres como se muestra en el gráfico 11. En el rango de edad entre 35 y 39 años, los mayores beneficiarios son los hombres con un total de 128 de los subsidios asignados, 32 más que las mujeres del mismo rango de edad.

Tanto en el rango de 25 a 29 años como en el de 30 a 34 años, a las mujeres les fueron asignados más subsidios que a los hombres, esto es consecuente con la diferencia en la tasa de desempleo femenino y masculina, sin embargo, la diferencia no es significativa si se tienen en cuenta las tasas de desempleo por género y por rango de edad. 


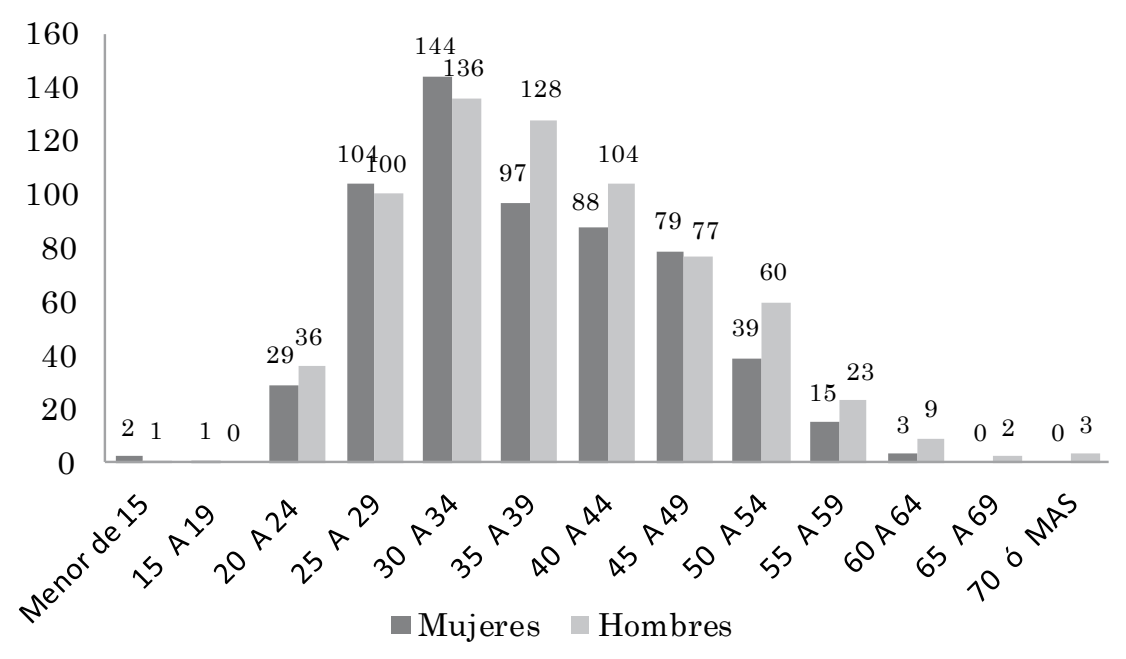

Gráfico 11. Número de subsidios asignados por sexo y rango de edad. Comfacauca. 2011.

Fuente: elaboración propia a partir de Comfacauca (2011).

Al clasificar los subsidios asignados por sexo y, además, según el último salario que recibió la persona a quien se le asignó el subsidio, se encuentra que la gran mayoría de estos se entregan a personas que ganaron menos de tres salarios mínimos. Según esta clasificación, dentro de estos dos rangos salariales, a los hombres les son asignados más subsidios que a las mujeres. Por encima de estos rangos salariales son mínimos los subsidios asignados por la Caja de Compensación Familiar Comfacauca. Finalmente, el máximo nivel de formación alcanzado por los beneficiarios del subsidio es bachillerato, tanto para hombres como para mujeres, le siguen el nivel técnico en el caso de las mujeres y el nivel de primaria en el caso de los hombres.

\section{Oferta y demanda de empleo en Popayán}

A partir de las brechas detectadas entre la oferta y demanda laboral en la ciudad de Popayán, es pertinente contrastar esos resultados con la información suministrada por las empresas de servicios temporales, las cuales en la práctica se han convertido en importantes intermediarios entre oferentes y demandantes del mercado de trabajo local. 


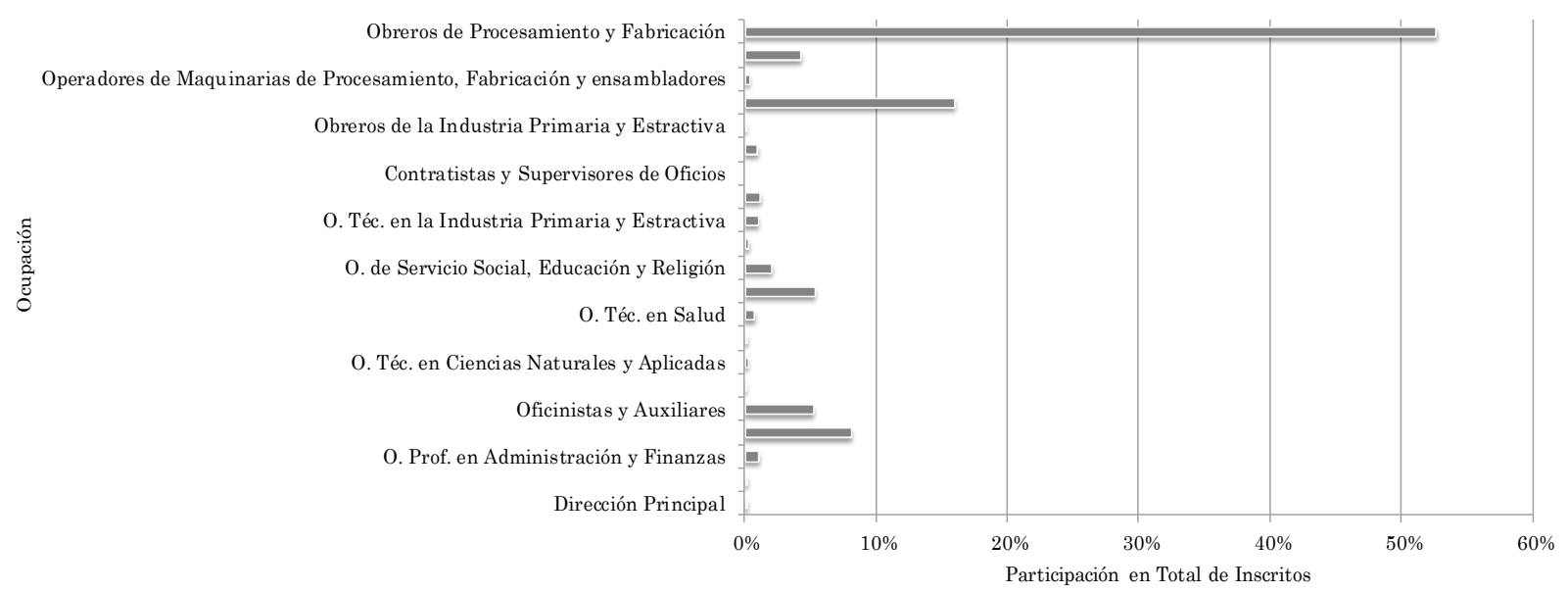

Gráfico 12. Participación en total de inscritos (oferta) a empresas de servicios de temporales según ocupación. Popayán. 2012.

Fuente: elaboración propia a partir del Ministerio de Trabajo, Seccional Cauca (2012).

El gráfico anterior devela que el mayor número de inscritos corresponde a la ocupación de obreros de procesamiento y fabricación con 929 inscritos, lo cual corresponde al 53\% del total. En segundo lugar, se encuentran los supervisores y ocupaciones técnicas en procesamiento, fabricación y suministro de servicios públicos con 282 inscritos, representando el $16 \%$ del total. En tercer lugar, se ubican las ocupaciones administrativas con 143 inscritos, correspondiente al 8\% del total.

La información sobre el número de inscritos a las empresas de servicios temporales también se encuentra clasificada por edad y sexo. El mayor número de inscritos se encuentra en el rango de edad de 25-29 años con 754 inscritos, de los cuales el $27 \%$ corresponde a mujeres y $16 \%$ a hombres con respecto al total de inscritos. En segundo lugar, se encuentra el rango de edad de 20-24 años con 534 inscritos, de los cuales el $20 \%$ corresponde a hombres y $11 \%$ a mujeres con respecto al total de inscritos. En tercer lugar, se encuentra el rango de edad de 30-34 años con 269 inscritos, de los cuales el $11 \%$ corresponde a hombres y $4 \%$ a mujeres con respecto al total de inscritos. De otro lado, para el año 2012 el número total de requisiciones de personal, las cuales constituyen una proporción de la demanda de empleo del municipio, fue de 1.667 . 
El gráfico muestra que el mayor número de requisiciones (demanda) corresponde a la ocupación de obreros de procesamiento y fabricación con 929 requisiciones, lo cual corresponde al 56\% del total. En segundo lugar, se encuentran los supervisores y ocupaciones técnicas en procesamiento, fabricación y suministro de servicios públicos con 177 requisiciones, representando el 11\% del total. En tercer lugar, se ubican los operadores de maquinarias de procesamiento, fabricación y ensambladores con 126 requisiciones, correspondientes al 8\% del total.
A partir del gráfico anterior se puede encontrar que el mayor número de colocaciones corresponde a la ocupación de obreros de procesamiento y fabricación, con 929 colocados, lo cual corresponde al 56\% del total. En segundo lugar, se encuentran los supervisores y ocupaciones técnicas en procesamiento, fabricación y suministro de servicios públicos, con 252 colocados, representando el 15\% del total. En tercer lugar, se ubican las ocupaciones administrativas, con 119 colocados, los cuales corresponden al $7 \%$ del total.

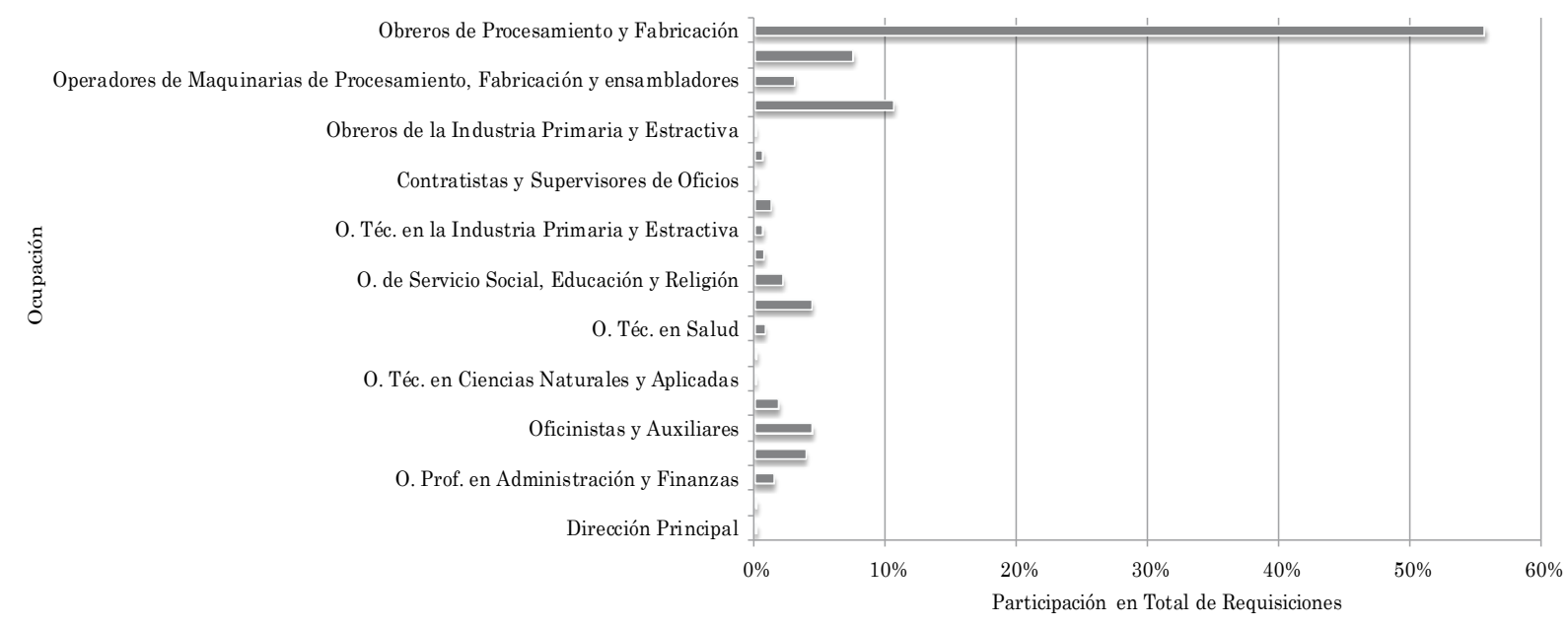

Gráfico 13. Participación en total de requisiciones (demanda) a empresas de servicios de temporales según ocupación. Popayán. 2012.

Fuente: elaboración propia a partir del Ministerio de Trabajo, Seccional Cauca (2012). 


\section{Super} Operadores de Maquinarias de Procesamiento, Fabricación y ensambladores Operadores de Maquinarias de Procesamiento, Fabricación y ensambladores Supervisores y O. Téc. en Procesamiento, Fabricación y Suministro de Serv. Púb. Obreros de la Industria Primaria y Estractiva Oficios, Operadores de Equipos y Transporte Contratistas y Supervisores de Oficios O. Elementales en Ventas y Servicios O. Téc. en la Industria Primaria y Estractiva O. Intermedias en Ventas y Servicios O. de Servicio Social, Educación y Religión O. Auxiliares en Servicios de la Salud

O. Téc. en Salud

O. Téc. en Ciencias Naturales y Aplicadas O. Prof. en Ciencias Naturales y Aplicadas Oficinistas y Auxiliares O. Administrativas O. Prof. en Administración y Finanzas Gerencia Media
Dirección Principal

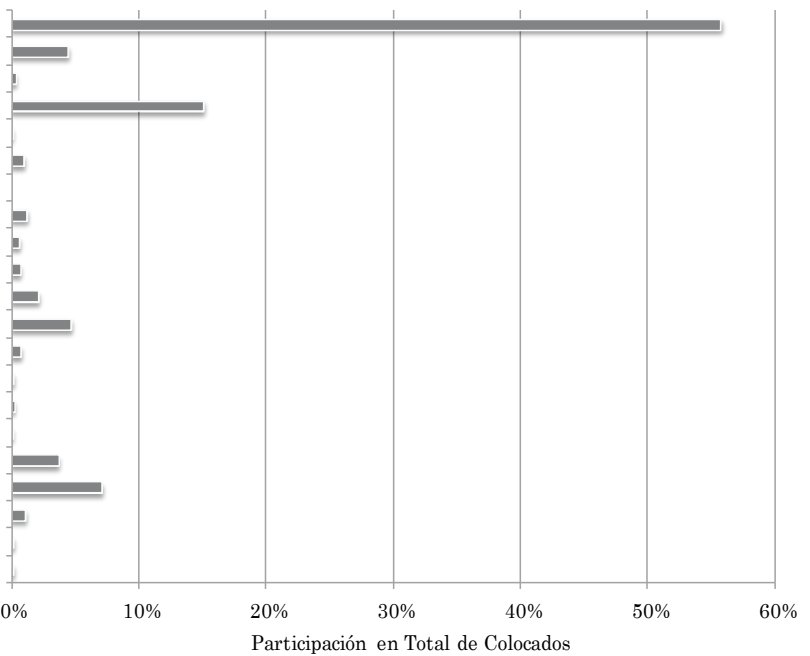

Gráfico 14. Total de requisiciones cubiertas (colocados) a empresas de servicios de temporales según ocupación. Popayán. 2012.

Fuente: elaboración propia a partir del Ministerio de Trabajo, Seccional Cauca (2012).

Finalmente, para el año 2012 el número total de requisiciones de personal cubiertas, las cuales constituyen la cantidad de inscritos que lograron colocarse en el mercado laboral del municipio, fue de 1.666 .

Finalmente, se puede analizar en forma conjunta el total de inscritos frente al total de requisiciones realizadas a empresas de servicios de temporales según ocupación para el período de análisis. El cuadro siguiente permite identificar desbalances entre la oferta y demanda de empleo en la ciudad de Popayán con el fin de aportar elementos para guiar la movilidad del factor trabajo hacia sectores que lo están demandando.

De las 21 ocupaciones con inscritos y requisiciones, ocho presentan una situación de equilibrio, es decir, el total de inscritos por cada ocupación corresponde exactamente al total de requisiciones realizadas a las EST. Siete de ellas se encuentran en abundancia, es decir que el total de ins- 


\section{Cuadro 5}

Balance entre el total de inscritos (oferta) y el total de requisiciones (demanda) a empresas de servicios de temporales según ocupación. Popayán. 2012.

\begin{tabular}{|c|c|c|c|c|}
\hline Nombre de la Ocupación & $\begin{array}{l}\text { No. Inscritos } \\
\text { (Oferta) }\end{array}$ & $\begin{array}{l}\text { No. Requisiciones } \\
\text { (Demanda) }\end{array}$ & $\begin{array}{c}\text { Balance } \\
(\mathrm{O}-\mathrm{D})\end{array}$ & Descripción \\
\hline Dirección Principal & 3 & 3 & 0 & Equilibrio \\
\hline Gerencia Media & 3 & 3 & 0 & Equilibrio \\
\hline O. Prof. en Administración y Finanzas & 19 & 25 & -6 & Escasez \\
\hline O. Administrativas & 143 & 65 & 78 & Abundancia \\
\hline Oficinistas y Auxiliares & 92 & 74 & 18 & Abundancia \\
\hline O. Prof. en Ciencias Naturales y Aplicadas & 1 & 31 & -30 & Escasez \\
\hline O. Téc. en Ciencias Naturales y Aplicadas & 4 & 1 & 3 & Abundancia \\
\hline O. Prof. en Salud & 3 & 3 & 0 & Equilibrio \\
\hline O. Téc. en Salud & 13 & 13 & 0 & Equilibrio \\
\hline O. Auxiliares en Servicios de la Salud & 94 & 73 & 21 & Abundancia \\
\hline O. de Servicio Social, Educación y Religión & 36 & 36 & 0 & Equilibrio \\
\hline O. Intermedias en Ventas y Servicios & 5 & 12 & -7 & Escasez \\
\hline O. Téc. en la Industria Primaria y Estractiva & 18 & 11 & 7 & Abundancia \\
\hline O. Elementales en Ventas y Servicios & 21 & 21 & 0 & Equilibrio \\
\hline Contratistas y Supervisores de Oficios & 0 & 1 & -1 & Escasez \\
\hline Oficios, Operadores de Equipos y Transporte & 17 & 11 & 6 & Abundancia \\
\hline $\begin{array}{l}\text { Obreros de la Industria Primaria y } \\
\text { Estractiva }\end{array}$ & 1 & 1 & 0 & Equilibrio \\
\hline $\begin{array}{l}\text { Supervisores y O. Téc. en Procesamiento, } \\
\text { Fabricación y Suministro de Serv. Púb. }\end{array}$ & 282 & 177 & 105 & Abundancia \\
\hline $\begin{array}{l}\text { Operadores de Maquinarias de } \\
\text { Procesamiento, Fabricación y ensambladores }\end{array}$ & 6 & 51 & -45 & Escasez \\
\hline $\begin{array}{l}\text { Operadores de Maquinarias de } \\
\text { Procesamiento, Fabricación y ensambladores }\end{array}$ & 75 & 126 & -51 & Escasez \\
\hline Obreros de Procesamiento y Fabricación & 929 & 929 & 0 & Equilibrio \\
\hline
\end{tabular}

Fuente: elaboración propia a partir del Ministerio de Trabajo, Seccional Cauca (2012). 
critos superan al total de requisiciones, reflejando condiciones de desempleo en ocupaciones administrativas; oficinistas y auxiliares; técnicos en ciencias naturales y aplicadas; auxiliares en servicios de salud; técnico en industria primaria y extractiva; oficios, operadores de equipos y transporte; supervisores y operadores técnicos en procesamiento, fabricación y suministro de servicios públicos. Por último, seis de ellas presentan escasez de trabajadores, dado que la oferta es menor frente a la demanda de estas ocupaciones, tales como profesionales en administración y finanzas; en ciencias naturales y aplicadas; operarios en ventas y servicios; contratistas y supervisores de oficios; operadores de maquinarias de procesamiento, fabricación y ensambladores.

\section{Conclusiones}

El comercio es el sector que más concentración de empresas tiene, caracterizado por presentar altos niveles de informalidad y baja inversión en activos, lo cual genera un impacto negativo en la productividad del factor, redundando en bajos niveles salariales. Adicionalmente, la mayoría de empresas registradas son microempresas, es decir, establecimientos cuyo número de trabajadores no supera los 10 empleados, por lo tanto, la generación potencial de empleo de este tipo de empresas no excede los 75.000 .

En términos generales el departamento del Cauca se caracteriza por tener una economía volátil, baja industrialización, altos niveles de desempleo, pobreza, concentración del ingreso, bajos ingresos per cápita, y adicionalmente, es permeada profundamente por el conflicto armado y la corrupción. Estos problemas van en contra de lograr fomentar el empleo, por tanto, se requiere de una política pública en diferentes escenarios que fomenten un mejor clima para atraer empresas del sector real que generen empleo.

El departamento del Cauca ha mostrado en su historia reciente que su economía depende básicamente de tres sectores: el sector agrícola, industrial y, actualmente, del sector comercial y de servicios. En el primer sector los niveles de contratación son bajos ya que la mayoría de los trabajadores son los mismos dueños de la tierra (o en el peor de los casos han sido despojados de ella) y los niveles de capital humano que se requieren son mínimos, lo que va en detrimento de la productividad. A pesar de que el subsector cafetero genera a nivel rural alrededor de 50.000 empleos, su participación sigue siendo baja dentro 
del total de la población económicamente activa del Cauca. Para el segundo, los empleos generados son de mandos bajos y medios, pero las altas gerencias pertenecen a trabajadores de otra región. El sector de servicios muestra dificultades frente al empleo, ya que el sector público y privado contrata por medio de recomendaciones, las universidades públicas están en crisis y cada vez demandan menos empleos fijos, el sector salud también enfrenta una de sus peores crisis y los servicios domésticos no necesitan tampoco altas cualificaciones. Finalmente, el sector comercial genera una gran cantidad de empleos de carácter informal, y es un sector que depende ostensiblemente del ciclo económico.

En términos generales, el Cauca presenta unos socios comerciales que no favorecen la estabilidad de la balanza comercial, ya que los productos caucanos son vendidos a países de Suramérica, es decir, a economías en vía de desarrollo, y se compran productos a países en su mayoría desarrollados. Esto implica que las exportaciones serán más volátiles hacia futuro que las importaciones, conllevando a que seguramente la balanza comercial continuará por mucho tiempo deficitaria, lo que implica, a su vez, que el sector externo no ayudará a mejorar en el mediano plazo, por ejemplo, al desempleo en el departamento.
Popayán tiene un desempleo que se caracteriza por ser uno de los más elevados a nivel nacional (alrededor del 19,1\% en promedio para el periodo analizado 2007 2012), focalizado más en las mujeres que en los varones. En el caso de los varones, el promedio entre los años se encontró en $31 \%$ y para las mujeres en $39 \%$, además, con la tendencia a que la brecha se amplíe, puesto que el desempleo juvenil para los hombres disminuyó más rápido que el de las mujeres. La situación de desempleo de las mujeres en Popayán es crítica. El indicador por género que existe sobre desempleo muestra que a nivel local siempre las mujeres están liderando las cifras más elevadas. Es decir, la poca demanda de trabajadores existente es copada generalmente por hombres.

La economía payanesa muestra una relación directa con los sectores generadores de empleo. El sector de comercio y el sector de servicios jalonan la economía local y es allí donde se concentra más del $60 \%$ del empleo en la ciudad, como era de esperarse. Estos sectores se caracterizan por presentar demandas frágiles y además estacionales. Por tanto, existe un círculo vicioso difícil de romper: no existe un sector que genere empleos de calidad, estables y bien remunerados, y las únicas alternativas de empleo están en los sectores de alta volatilidad. Por consiguiente, la meta es 
potenciar un sector más estable que sea de alto impacto económico, que corresponda con la cultura de la región, con su geografía, con su situación de orden público y con sus posibilidades para generar más y mejores empleos.

Actualmente existen esfuerzos por potenciar varios sectores como el turístico, el cual es un sector que al operar en red requiere inversión en carreteras, hospitales, infraestructura propia y apoyo político, entre otros, siendo los recursos geográficos y la cualificación de mano de obra los únicos factores con que cuenta específicamente el departamento, éste último a través del pregrado en turismo de la Universidad del Cauca. Por tal motivo, se deben impulsar otros sectores que estén un poco menos a merced de los ciclos económicos tanto internos como externos. A manera de hipótesis se considera que el sector educativo podría ser el protagonista ya que se cuenta no sólo con la infraestructura, sino con la capacidad profesional y técnica para consolidarlo, aunque debe hacerse hacia futuro un estudio a profundidad para poder decidir si efectivamente este es el sector líder.

A pesar de que la ciudad no cuenta con una caracterización más estructurada o precisa de los niveles de informalidad que den cuenta, por ejemplo, de la distribución por sexo, por edades, por profesiones o por sector económico, el estudio referenciado en el documento muestra que la informalidad es demasiado alta, lo que hace necesario para cualquier toma de decisiones de política pública acertada realizar una investigación con información de microdatos para lograr acercarse mucho más al entendimiento de éste fenómeno y poder mitigar su impacto.

La información suministrada por la Caja de Compensación Familiar del Cauca (Comfacauca, 2011), muestra que en las capacitaciones hay una mayor participación de los hombres, así como en los subsidios al desempleo en varios rangos de edad. Aunque estos programas ayudan a mejorar las condiciones de los empleados y sus posibilidades de colocarse en el mercado laboral, dado que la tasa de desempleo femenina es más alta que la masculina, debería ser política de la caja de compensación focalizar preferentemente este tipo de instrumentos hacia las mujeres.

Finalmente, en la caracterización de la oferta y demanda de empleo para la ciudad de Popayán, se observa la asimetría entre el número de personas que aplican con el fin de insertarse en el mercado laboral y el número de requisiciones de las diferentes instituciones del orden local. También puede encontrarse que el mayor número de 
aplicaciones se encuentra en ocupaciones de baja cualificación, las cuales corresponden al tipo de demanda de empleo, pero en un número más bajo. Adicionalmente, se encuentra que el mayor número de aplicaciones lo representa la población femenina entre los 25 y 29 años.

\section{Recomendaciones para aminorar el desempleo}

a. El sector agrícola y ganadero debe protegerse por parte del Estado en tres aspectos: eliminar la gran cantidad de intermediarios para que el campesino y el ganadero tengan un mayor poder de negociación y, por ende, se procuren mejores ingresos; implementar subsidios en el corto $\mathrm{y}$ mediano plazo para protegerlos de la inestabilidad de los precios en los mercados internacionales; y elevar la productividad del sector para asegurar mejores salarios y una mayor competitividad.

b. Frente a la informalidad, para formular cualquier política pública en primer lugar se hace necesario realizar una investigación seria con información a nivel de microdatos que sean extraídos a nivel censal y no muestral. Adicionalmente, se re- quiere de su formalización para ganar mejores condiciones laborales e ingresos, al igual que la posibilidad del acceso a créditos con tasas preferenciales, sobre todo a los vendedores ambulantes.

c. En el caso de los altos niveles de desempleo en las mujeres payanesas se pueden considerar las siguientes estrategias:

- La formación para el trabajo de mujeres no cualificadas debe hacerse en actividades que generen un mayor impacto, no sólo para negocios como modistería, peluquerías, panaderías, artesanías, entre otros, ya que los niveles de productividad son muy bajos.

- Realizar convenios con las agremiaciones comerciales para que el sector contrate mujeres mayores de 35 años, pues la tendencia es contratar mujeres con mejores perfiles físicos.

- Impulsar con un programa la puesta en práctica de la Ley 1257 de 2008 , la cual entre otras cosas, genera exenciones tributarias a los negocios que empleen a mujeres víctimas de cualquier tipo de violencia. 
- Generar acciones, por parte del Estado, de discriminación positiva para mujeres cabeza de familia. En este caso, emprender un proyecto sobre guarderías para madres que aliviane su carga reproductiva, estén empleadas o no.

- Apoyar financieramente los proyectos de empleabilidad que se implementarán en la Secretaría de la Mujer del Cauca.

- El apoyo para proyectos productivos a mujeres no cualificadas no sólo debe hacerse con recursos financieros sino con capacitaciones de gestión administrativa y económica que permitan que los negocios tengan una mayor durabilidad y prosperidad.

d. Para lograr desentramar y combatir el problema del desempleo bajo el complejo escenario social, económico y político del departamento, se requiere de un sistema de información integrado que consolide en tiempo real la información generada en dichos aspectos por todos los actores de índole público, privado y comunitario que permitan conocer en primer lugar los factores que generan el desempleo, para que en segundo lugar, se pueda impulsar la implementación de políticas públicas más acertadas.

\section{Referencias}

DANE. (2007). Informe Coyuntura Económica Regional-ICER. Departamento del Cauca. Bogotá: Banco de la República.

DANE. (2008). Informe Coyuntura Económica Regional-ICER. Departamento del Cauca. Bogotá: Banco de la República.

DANE. (2009). Informe Coyuntura Económica Regional-ICER. Departamento del Cauca. Bogotá: Banco de la República.

DANE. (2010). Informe Coyuntura Económica Regional-ICER. Departamento del Cauca. Bogotá: Banco de la República.

DANE. (2011). Informe Coyuntura Económica Regional-ICER. Departamento del Cauca. Bogotá: Banco de la República.

DANE. (2012). Informe Coyuntura Económica Regional-ICER. Departamento del Cauca. Bogotá: Banco de la República.

DANE. (2012). GEIH. Recuperado de https://www.dane.gov.co/index.php/ estadisticas-por-tema/mercado-laboral/ empleo-y-desempleo/geih-historicos

Cámara de Comercio del Cauca. (2009). 200 Empresas Generadoras de Desarrollo en el Cauca. Popayán: Cauca Progresa.

Comfacauca. (2011). Caja de Compensación Familiar del Cauca. Recuperado de http://www.comfacauca.com 
Departamento Nacional de Planeación DNP. (2011). Informe de Seguimiento de los Objetivos del Nuevo Milenio. Análisis Regional: Colombia 2011. Recuperado de http://www.undp.org/content/dam/undp/library/MDG/english/ MDG\%20Country\%20Reports/Colombia/mdgrcolombia2011.pdf

Galvis, L. (2010). Diferenciales salariales por género y región en Colombia: una aproximación con regresión por cuantiles. Revista de Economía del Rosario, 13(2) 235-277.

Galvis, L. y Meisel, A. (2012). Convergencia y trampas espaciales de pobreza en Colombia: Evidencia reciente. Documentos de trabajo Sobre Economía Regional. 77 .

Gómez, M., Miller, A. y Rivera, I. (2006). Análisis y Predicción de la Economía del Cauca. Popayán: Universidad del Cauca.

Gómez, M. (2010). Productividad Multifactorial del Sector Manufacturero del Cauca 1993-2006. Sociedad y Economía, 20. 243-265.

Miller, A. y Gómez, M. (2011). Análisis del Impacto Socioeconómico de las denominadas "Pirámides" en el Departamento del Cauca 2006-2008. Semestre Económico. 14(28). 11-33.
Gómez, M. (2011). Análisis de la Interdependencia de los Ciclos Económicos del Cauca y el Suroccidente Colombiano: Una Aproximación Econométrica Desde los Filtros de Kalman y Hodrick-Prescott. Estudios Gerenciales, 27(121). 111-136.

Mendoza, O. y Sarmiento, J. (2005). Impacto del Sector Financiero en el nivel de actividad económica del Cauca (Tesis). Universidad del Cauca, Popayán.

República de Colombia. Ministerio de Trabajo. (2012). Seccional Cauca. Recuperado de http://www.mintrabajo.gov.co/

República de Colombia. Congreso de la República. Ley 218. (17 de noviembre de 1995). Por la cual se modifica el Decreto 1264 del 21 de junio de 1994 proferido en desarrollo de la emergencia declarada mediante Decreto 1178 del 9 de junio de 1994 y se dictan otras disposiciones. Diario Oficial 42.117, Bogotá, D. C.: Imprenta Nacional de Colombia.

República de Colombia. Congreso de la República. Ley 590. (10 de julio de 2010). Por la cual se dictan disposiciones para promover el desarrollo de las micro, pequeñas y medianas empresa. Diario Oficial 44078, Bogotá, D. C.: Imprenta Nacional de Colombia. 